Revista Brasileira de Informática na Educação - RBIE Brazilian Journal of Computers in Education (ISSN online: 2317-6121; print: 1414-5685) http://br-ie.org/pub/index.php/rbie

Submission: 21/Mar/2021;

Camera ready: 19/Jun/2021; $1^{\text {st }}$ round notif.: 28/May/2021; Edition review: 21/Jun/2021;
New version: $12 / \mathrm{Jun} / 2021$; Available online: 28/Jun/2021; $2^{\text {nd }}$ round notif.: 19/Jun/2021;

Published: $28 / \mathrm{Jun} / 2021$;

\title{
Computação Fundamental: Currículo e Livros Didáticos de Computação para o Ensino Fundamental II
}

\section{Title: Fundamental Computing: Computing Curriculum and Textbooks for Middle School}

Roberto A. Bittencourt UEFS - Universidade

Estadual de Feira de Santana roberto@uefs.br

\author{
Bianca L. Santana \\ UEFS - Universidade \\ Estadual de Feira de Santana \\ biancasantana.ls@gmail.com
}

\author{
Luis Gustavo J. Araújo \\ UEFS - Universidade \\ Estadual de Feira de Santana \\ luisaraujo.ifba@gmail.com
}

\begin{abstract}
Resumo
Dada a relevância da computação na sociedade contemporânea, seja por sua pervasividade e impacto, seja pelo seu potencial em facilitar a expressão flexível, a comunicação, o desenvolvimento do pensamento computacional e as habilidades do Século XXI, seja pelas oportunidades de carreira oferecidas nesta área, é cada vez mais comum a adoção da computação nos currículos da educação básica. Este artigo descreve o currículo denominado Computação Fundamental, uma implementação de currículo e livros-texto para a segunda etapa do Ensino Fundamental brasileiro. O currículo fundamenta-se em currículos em espiral, na aprendizagem significativa, em projetos construcionistas e na contextualização da aprendizagem de computação. Os livros didáticos associados oferecem um guia para professores e atividades para estudantes que permitem conhecer elementos básicos da computação e realizar práticas de computação e reflexões a partir da prática. As primeiras experiências com o currículo apontam desafios de implementação em termos de infraestrutura, capacitação docente e integração com os currículos escolares existentes, mas também descortinam potenciais efeitos positivos em sua adoção em termos de expressão criativa, formação interdisciplinar, motivação e engajamento estudantil e melhor retenção do conhecimento.
\end{abstract}

Palavras-chave: Currículo; Livro Didático; Computação; Educação Básica; Ensino Fundamental II.

\begin{abstract}
Given the relevance of computing in contemporary society, whether for its pervasiveness and impact, or for its potential to facilitate flexible expression, communication, development of computational thinking and 21 st century skills, or even for career opportunities in this field, it is becoming more common to add computing to primary education curricula. This article describes the curriculum entitled Fundamental Computing, an implementation of curriculum and textbooks for the second stage of Brazilian Primary Education. The curriculum is based on spiral curriculum, meaningful learning, constructionist projects and contextualizing learning of computing. The associated textbooks offer a guide for teachers and activities for students that allow them to learn basic elements of computing and carry out practices of computing and reflections from practice. The first experiences with the curriculum point to implementation challenges in terms of infrastructure, teacher professional development and integration with existing school curricula. On the other hand, they also reveal potential positive effects in its adoption in terms of creative expression, interdisciplinary learning, student motivation and engagement, and knowledge retention.
\end{abstract}

Keywords: Curriculum; Textbook; Computing; Primary Education; Middle School.

Cite as: Bittencourt, R. A., Santana, B. L., \& Araujo, L. G. J. (2021). Computação Fundamental: Currículo e Livros Didáticos de Computação para o Ensino Fundamental II. Revista Brasileira de Informática na Educação, 29, 662-691. DOI: 10.5753/RBIE.2021.29.0.662. 


\section{Introdução}

Aprender computação tem se tornado mais relevante para a sociedade contemporânea por razões importantes: por sua pervasividade na vida humana (Castells, 1996), pelo poder de expressão e comunicação que computadores dão a quem os sabem programar (Resnick, 2012), por auxiliar no desenvolvimento do pensamento (Wing, 2006; diSessa, 2018), por auxiliar na formação de habilidades importantes do Século XXI (Mioto, Petri, von Wangenheim, Borgatto, \& Pacheco, 2019) ou por abrir um leque de carreiras atraentes para profissionais da área (Observatório Softex, 2012). (Pressman, 2011)

Depois de algumas iniciativas parcialmente frustradas de introduzir a computação na educação básica entre os anos 1970 e 2000, o mundo retomou de forma vigorosa, no início do Século XXI, a tendência de introduzir a computação na educação básica (CSforAll, 2021; Computing at School, 2021). Currículos têm sido produzidos em diferentes países, como nos Estados Unidos (Computer Science Teachers Association, 2017), Reino Unido (Royal Society, 2012), Coreia do Sul (Choi, An, \& Lee, 2015) e muitos outros (Hubwieser et al., 2015; Szabo, Sheard, LuxtonReilly, Becker, \& Ott, 2019). Em alguns países, o ensino médio já considera a computação como disciplina compulsória e, aos poucos, ela começa a ser introduzida na educação infantil e no ensino fundamental (Szabo et al., 2019).

No Brasil, a Sociedade Brasileira de Computação (SBC) tem trabalhando ativamente na construção de referenciais curriculares (SBC, 2017) e diretrizes (SBC, 2018) para a introdução da computação na educação básica, além de envidar esforços junto ao Conselho Nacional de Educação (CNE) para que a computação faça parte da Base Nacional Comum Curricular (BNCC) dos ensinos fundamental e médio (Brasil/MEC, 2018), já que estes documentos hoje mencionam a computação e tecnologias de informação como relevantes, mas não as abraçam por inteiro. Além da SBC, outras instituições, como o CIEB, tem oferecido contribuições prolíficas na forma de referenciais curriculares de computação para a educação básica, demonstrando o interesse da sociedade civil brasileira na curricularização da computação na educação básica (CIEB, 2018).

As iniciativas curriculares anteriores são, obviamente, relevantes para o avanço da curricularização da computação, mas são limitadas por seu nível mais abstrato de construção, elencando tópicos de conteúdo e objetivos de aprendizagem. Para uma percepção mais concreta das possibilidades da computação na educação básica brasileira, seria importante contar com materiais didáticos detalhados, organizados temporalmente e buscando alcançar objetivos de aprendizagem definidos nos referenciais curriculares. Em alguns mapeamentos sistemáticos e surveys sobre a computação na educação básica no Brasil, são destacadas inúmeras iniciativas de pesquisadores em vários níveis de ensino, mas são praticamente inexistentes os trabalhos que tratam de implementações curriculares detalhadas, especialmente no Ensino Fundamental (Santos, Araujo, \& Bittencourt, 2018; Bordini et al., 2016).

Este trabalho, portanto, pretende suprir esta lacuna, provendo um currículo de computação para o Ensino Fundamental II, organizado temporalmente do sexto ao nono anos, em conjunto com recursos didáticos associados, i.e., livros didáticos e materiais de apoio para cada um dos anos do Ensino Fundamental II.

Nosso projeto, intitulado Computação Fundamental, agrega o currículo e os recursos didáticos desenvolvidos para suprir o objetivo anterior. Em termos curriculares, nosso currículo se 
sustenta nos referenciais da Computer Science Teachers Association (CSTA), por seu nível detalhado de descrição dos objetivos de aprendizagem e por seu uso já bem sucedido nos EUA, embora haja convergência razoável entre o currículo da CSTA e os referenciais desenvolvidos no Brasil. Em termos dos recursos didáticos, os livros e materiais de apoio desenvolvidos foram disponibilizados para a comunidade de forma gratuita e com uma licença Creative Commons, o que permite o reuso dos materiais desenvolvidos. Os livros foram publicados formalmente em versões para o professor (Santana, Araujo, \& Bittencourt, 2019b; Araujo, Santana, \& Bittencourt, 2019b; Santana, Araujo, \& Bittencourt, 2020b; Araujo, Santana, \& Bittencourt, 2020b) e versões para o estudante (Santana, Araujo, \& Bittencourt, 2019a; Araujo, Santana, \& Bittencourt, 2019a; Santana, Araujo, \& Bittencourt, 2020a; Araujo, Santana, \& Bittencourt, 2020a).

Este trabalho agrega ideias de outros artigos (Santana, Araujo, \& Bittencourt, 2019c; Araujo, Santana, \& Bittencourt, 2019c; Santana, Araujo, \& Bittencourt, 2020c; Araujo, Santana, \& Bittencourt, 2020c), estendendo-os, especialmente o mais recente destes (Araujo et al., 2020c). O objetivo deste artigo, portanto, é de apresentar integralmente o currículo Computação Fundamental e seus livros didáticos associados, adicionando a dimensão dos fundamentos teóricos que sustentam o currículo, provendo uma visão integrada do currículo e fomentando o debate na comunidade acadêmica brasileira, e na comunidade lusófona de forma mais ampla, sobre as possibilidades de implementações detalhadas de currículos de computação para a educação básica.

\section{Fundamentos}

O currículo Computação Fundamental usa um conjunto de diferentes bases teóricas sobre aprendizagem. Esta seção apresenta os principais fundamentos teóricos que embasam o currículo, como currículo em espiral, aprendizagem significativa, construcionismo, contextualização da aprendizagem de computação, além de destacar outros elementos importantes para a concepção do currículo, como referenciais curriculares de computação para a educação básica.

\subsection{Currículo em Espiral}

Jerome Bruner, em um trabalho seminal, afirmava: "Começamos com a hipótese que qualquer assunto pode ser ensinado de alguma forma intelectualmente honesta a qualquer criança em qualquer estágio de desenvolvimento" (Bruner, 1966). A partir desta afirmação, nasceu a ideia de currículo em espiral. Embora as definições de Bruner inicialmente se preocupem mais com as etapas da aprendizagem de crianças, por ele chamadas de enativa, icônica e simbólica, a organização do conhecimento proposta acabou sendo adotada por currículos de ciências em todo o mundo, em diferentes fases da formação dos estudantes (Herr, 2008).

De modo geral, o currículo em espiral possui as seguintes características: 1) Os estudantes revisitam um tópico ou assunto várias vezes durante sua vida escolar; 2) A complexidade do tópico aumenta a cada revisita; 3) O novo aprendizado apresenta relações com o aprendizado prévio, sendo a informação nova contextualizada com a informação antiga (Herr, 2008). O currículo em espiral permite que o conhecimento seja reforçado e solidificado a cada revisita, permitindo a progressão de ideias mais simplistas para outras mais complexas, encorajando os estudantes a aplicarem conhecimentos prévios em etapas posteriores. 
Em nosso currículo, tópicos de computação são revisitados ao longo das diferentes unidades e livros. Por exemplo, estruturas algorítmicas de seleção, repetição e subprogramas são inicialmente apresentadas no sexto ano através de quebra-cabeças desplugados, revisitadas através da programação em blocos desenhando figuras com a caneta do Scratch no sétimo ano, retomadas no processamento de imagens com GPBlocks na terceira unidade do oitavo ano, reapresentadas com o desenho de figuras com turtle graphics na linguagem textual Python na quarta unidade deste mesmo ano, e revistas na programação de jogos textuais e numéricos usando o console em Python no nono ano, acrescentando complexidade e nuances a cada revisita. $\mathrm{O}$ mesmo ocorre com vários contextos metodológicos ou domínios de aplicação, como foi o caso citado do desenho de figuras, inicialmente na linguagem de blocos de Scratch e, em seguida, na programação da biblioteca turtle em Python.

\subsection{Aprendizagem Significativa}

Ausubel criticava a aprendizagem mecânica comum na educação regular, onde as informações são memorizadas sem uma relação com conhecimentos prévios do aprendiz, oferecendo a alternativa de aprendizagem significativa, onde nova informação é apreendida e relacionada com conhecimentos prévios existentes na estrutura cognitiva do aprendiz, auxiliando numa compreensão mais profunda e significativa da nova informação. Para Ausubel, "aprendizagem é uma experiência consciente claramente articulada e precisamente diferenciada que emerge quando sinais, símbolos, conceitos ou proposições potencialmente significativos são relacionados e incorporados na estrutura cognitiva de um determinado indivíduo" (Ausubel, 1960).

Ausubel propõe a utilização explícita de organizadores prévios para servirem de ponte entre o que o aprendiz sabe e o que ele precisa saber para assimilar a nova informação (Ausubel, 1960). Organizadores prévios são recursos instrucionais que objetivam facilitar a aprendizagem, já que os aprendizes precisam ter subsunçores, conceitos relevantes armazenados em suas estruturas cognitivas, para que a aprendizagem significativa possa ocorrer.

Em nosso currículo, a aprendizagem significativa é apoiada por dois tipos de organizadores prévios. O primeiro é a recomendação explícita, na maior parte dos guias de condução de atividades pelos professores disponíveis nos livros para cada aula, de que os professores procurem resgatar os conhecimentos prévios de aulas anteriores para servirem de organizadores para o novo conhecimento a ser aprendido. O segundo é a própria organização do currículo em espiral, como descrito na subseção anterior, que permite que a visita anterior ao assunto ou a um contexto metodológico ou domínio de aplicação sirva como organizador prévio. Assim, por exemplo, ter aprendido estruturas de controle de forma desplugada, permite revisitá-las com aprendizagem mais significativa ao desenhar figuras em Scratch. Do mesmo modo, ter aprendido a desenhar figuras em Scratch facilita a aquisição da linguagem textual Python ao usar o desenho de figuras com a biblioteca Turtle como as primeiras atividades em uma linguagem textual.

\subsection{Construcionismo}

Papert sugeria que a descoberta e apropriação do conhecimento pode ocorrer melhor através da construção de artefatos (Papert, 1986). Através da aprendizagem construcionista, os estudantes criam modelos mentais para entender o mundo a seu redor. Para Papert, a aprendizagem é mais 
eficaz quando as pessoas estão ativas em fazer objetos tangíveis no mundo real.

Papert e colaboradores criaram a linguagem Logo como o objetivo de que os aprendizes desenvolvessem seu pensamento através da programação de computadores (Papert \& Solomon, 1971; Solomon et al., 2020). Através da linguagem Logo e, posteriormente, do uso de turtle graphics para desenhar figuras no chão através de um robô-tartaruga, estes pesquisadores permitiram o desenvolvimento de habilidades matemáticas como geometria e habilidades de programação como planejamento, execução, feedback e depuração.

Nosso currículo retoma os conceitos de desenho de figuras geométricas com Logo e turtle graphics através do uso da caneta em Scratch, através do movimento de um robô-carro em uma superfície, ou mesmo através da programação explícita da screen turtle em Python. Além disso, durante todos os anos do currículo, os estudantes são desafiados a construir artefatos, sejam físicos ou lógicos, onde podem exercer sua criatividade e descoberta. Vale ressaltar que adotamos uma visão pragmática, combinando instrução explícita nos momentos preliminares para familiarização com dado tópico ou contexto metodológico, seguido pela realização de projetos construcionistas. Neste sentido, não podemos afirmar que nosso currículo é integralmente construcionista, mas que apresenta elementos de construcionismo em sua composição.

\subsection{Contextualização da Aprendizagem de Computação}

Guzdial afirma que as pessoas aprendem computação por vários motivos (M. Guzdial, 2019). Por exemplo, podem aprender programação para terem uma ferramenta para lhes ajudar a pensar ou para terem uma ferramenta para 'aprender fazendo' sobre um dado tópico. Como a maior parte dos estudantes da educação básica não irão seguir uma carreira de tecnologia da informação, seus objetivos de aprender computação serão outros, mais ligados a auxiliá-los a pensar e fazer. Por isso, este autor defende o uso de contextos motivacionais para a aprendizagem de computação. Um contexto motivacional, às vezes na literatura chamado de contexto metodológico ou domínio de aplicação, é um contexto da computação relacionado a uma atividade do mundo real. Por exemplo, usar o computador para desenhar, gerar música, filtrar imagens, movimentar um robô, criar jogos, resolver quebra-cabeças traz contextos motivacionais para a aprendizagem da computação pois estão relacionados a atividades de interesse dos aprendizes, tipicamente, mas nem sempre, lúdicas.

M. Guzdial and Forte desenvolveram o contexto de computação com mídias ${ }^{1}$ para ensinar programação para estudantes da educação superior das áreas de artes e ciências sociais aplicadas, com o objetivo de aumentar a relevância para a audiência, prover espaço para a criatividade e tornar a experiência mais social (M. Guzdial \& Forte, 2005). No livro-texto mais conhecido sobre este contexto, são utilizados vários contextos de computação com mídias, como o processamento de imagens, o processamento de áudio, a manipulação de textos, a construção de páginas web e o processamento de vídeos (M. J. Guzdial \& Ericson, 2015). Por outro lado, Guzdial reconhece a diversidade de contextos possíveis para o ensino de computação para audiências mais amplas, como os citados no parágrafo anterior, como também as simulações de fenômenos científicos, a resolução de problemas matemáticos, dentre outros (M. Guzdial, 2019).

Nosso currículo é fértil no uso de contextos motivacionais: computação desplugada ao longo de todos os anos; uso do computador e desenvolvimento de animações no sexto ano; desenho de

\footnotetext{
${ }^{1}$ Eles usam o termo media computation em inglês para descrever o contexto.
} 
figuras, interação humano-computador e programação de jogos no sétimo ano; Internet, robótica educacional, processamento de imagens e desenho de figuras no oitavo ano; e simulações científicas, processamento de imagens, criação de jogos textuais e numéricos e hardware livre no nono ano. Muitas vezes, os contextos estão relacionados ao currículo em espiral, permitindo revisitar diferentes temas usando diferentes contextos, reforçando e solidificando os conhecimentos de computação em cada revisita. Os contextos foram selecionados a partir de atividades do mundo real de interesses dos aprendizes e organizados temporalmente de acordo com as mudanças de interesses dos estudantes ao longo dos anos do ensino fundamental, considerando a transição da infância para a adolescência e a complexidade própria dos contextos utilizados.

\subsection{Referenciais Curriculares de Computação na Educação Básica}

A Associação de Professores de Ciência da Computação ${ }^{2}$ (da sigla em inglês, CSTA) dos Estados Unidos tem desenvolvido referenciais curriculares detalhados para o ensino de computação na educação básica. Estes referenciais, em suas diversas versões, organizam o currículo em níveis educacionais e eixos de aprendizagem, destacando diferentes objetivos de aprendizagem para cada um dos níveis e eixos (Seehorn et al., 2011; Computer Science Teachers Association, 2017). Destacamos aqui a versão de 2011 do referenciais da CSTA, por terem sido usados durante a concepção do currículo Computação Fundamental.

Os referenciais da CSTA de 2011 definem três níveis de currículo, representando um conjunto específico de séries da educação básica. O primeiro nível, "Ciência da Computação e Eu", provê padrões para a séries da educação infantil até o equivalente ao sexto ano do ensino fundamental brasileiro, apresentando aos jovens estudantes conceitos fundamentais da computação, integrando habilidades básicas em tecnologia com ideias simples sobre pensamento computacional. O segundo nível, "Ciência da Computação e Comunidade" provê padrões para as séries equivalentes do sexto até o nono ano do ensino fundamental brasileiro, permitindo aos estudantes usar o pensamento computacional como uma ferramenta de resolução de problemas, usar a computação para facilitar a comunicação e colaboração e perceber o pensamento computacional como capaz de lidar com questões relevantes não apenas para eles, mas para o mundo ao seu redor. Já o terceiro nível, dividido em três cursos específicos, "Ciência da Computação no Mundo Moderno", "Princípios e Práticas da Ciência da Computação" e "Tópicos em Ciência da Computação", provê padrões para as séries equivalentes do nono ano do ensino fundamental brasileiro até o terceiro ano do ensino médio brasileiro, com cada curso específico focalizando em diferentes facetas da ciência da computação enquanto disciplina.

A versão de 2011 dos referenciais da CSTA define cinco eixos complementares e essenciais ao longo dos três níveis do currículo: 1) Pensamento Computacional, para resolver problemas, projetar sistemas e criar novo conhecimento; 2) Colaboração, já que projetos de computação tipicamente envolvem equipes de pessoas trabalhando juntas para produzir sistemas; 3) Práticas de Computação e Programação, que envolvem usar ferramentas computacionais para criar informação e programas; 4) Computadores e Dispositivos de Comunicação, para compreender os elementos dos modernos computadores, dispositivos de comunicação e redes de computadores e 5) Impactos Comunitários, Globais e Éticos, de modo a preparar os estudantes ao uso responsável das tecnologias no mundo atual, fazendo escolhas informadas e éticas. Finalmente, para cada um

\footnotetext{
${ }^{2}$ CSTA - Computer Science Teachers Association
} 
dos níveis de ensino e eixos essenciais descritos, os referenciais descrevem detalhadamente um conjunto de objetivos de aprendizagem a serem alcançados em implementações curriculares.

A Sociedade Brasileira de Computação (SBC) também tem desenvolvido referenciais e diretrizes curriculares para a adoção da computação na educação básica. Em 2017, a SBC lançou os Referenciais de Formação em Computação: Educação Básica (SBC, 2017). Estes referenciais descrevem a área de computação, três eixos centrais do ensino de computação e um conjunto de objetivos de aprendizagem para quatro níveis de ensino. Os três eixos centrais são: 1) Pensamento Computacional, relacionado a abstração, análise e automação; 2) Cultura Digital, relacionada a fluência digital, a ética digital e a computação e sociedade e 3) Mundo Digital, relacionado a atividades de codificação, processamento e distribuição da informação. Os níveis de ensino descritos são: 1) Educação Infantil; 2) Ensino Fundamental - Anos Iniciais; 3) Ensino Fundamental - Anos Finais e 4) Ensino Médio. Para cada um destes níveis são descritos objetivos mais sucintos do que o currículo do CSTA, e em torno dos três eixos de ensino.

A SBC também desenvolveu o documento Diretrizes para Ensino de Computação na Educação Básica, publicado em 2018 (SBC, 2018). Este documento descreve os seguintes elementos: 1) terminologia, 2) a área de computação, baseando-se nos eixos dos referenciais curriculares de 2017; 3) competências específicas da computação, relacionando-as com as competências gerais da Base Nacional Comum Curricular (BNCC); 4) os conceitos de computação relevantes para o ensino fundamental, sua distribuição temporal ao longo dos anos e suas dependências e 5) os conceitos de computação relevantes para o ensino médio e sua distribuição temporal.

Nosso currículo utiliza como referência curricular principal os referenciais curriculares da CSTA de 2011 descritos acima (Seehorn et al., 2011). O livro do sexto ano integra os principais objetivos de aprendizagem do primeiro nível, "Ciência da Computação e Eu", pressupondo-se a probabilidade de a maioria dos estudantes brasileiros iniciarem o sexto ano sem experiências prévias formais com a computação. Já os demais livros do sétimo ao nono anos utilizam os objetivos de aprendizagem do segundo nível, "Ciência da Computação e Comunidade", mais avançados que os do primeiro nível e centrados em torno da segunda etapa do ensino fundamental. Os objetivos escolhidos integram os eixos de aprendizagem do currículo da CSTA, ou seja, Pensamento Computacional, Colaboração, Práticas de Computação e Programação, Computadores e Dispositivos de Comunicação e Impactos Comunitários, Globais e Éticos, sendo descritos nas versões dos livros para o professor para cada aula planejada.

\section{Currículo}

Em nosso currículo, como descrito anteriormente, estruturamos os conhecimentos da computação e organizamos os resultados de aprendizagem em torno dos cinco eixos dos CSTA K-12 Computer Science Standards (Seehorn et al., 2011).

O eixo Pensamento Computacional (PC) considera que PC é uma abordagem para resolver problemas de modo que uma solução possa ser computada. Assim, PC envolve uma série de conceitos, como abstração e iteração, que são empregados para desenvolver soluções por meio da automação e análise. Em nossa abordagem, PC é apresentado como um modo de entrelaçar a computação com todas as disciplinas. Por isso, é um eixo que recebe destaque em todos os níveis. 


\section{COMPUTAÇÃO FUNDAMENTAL}

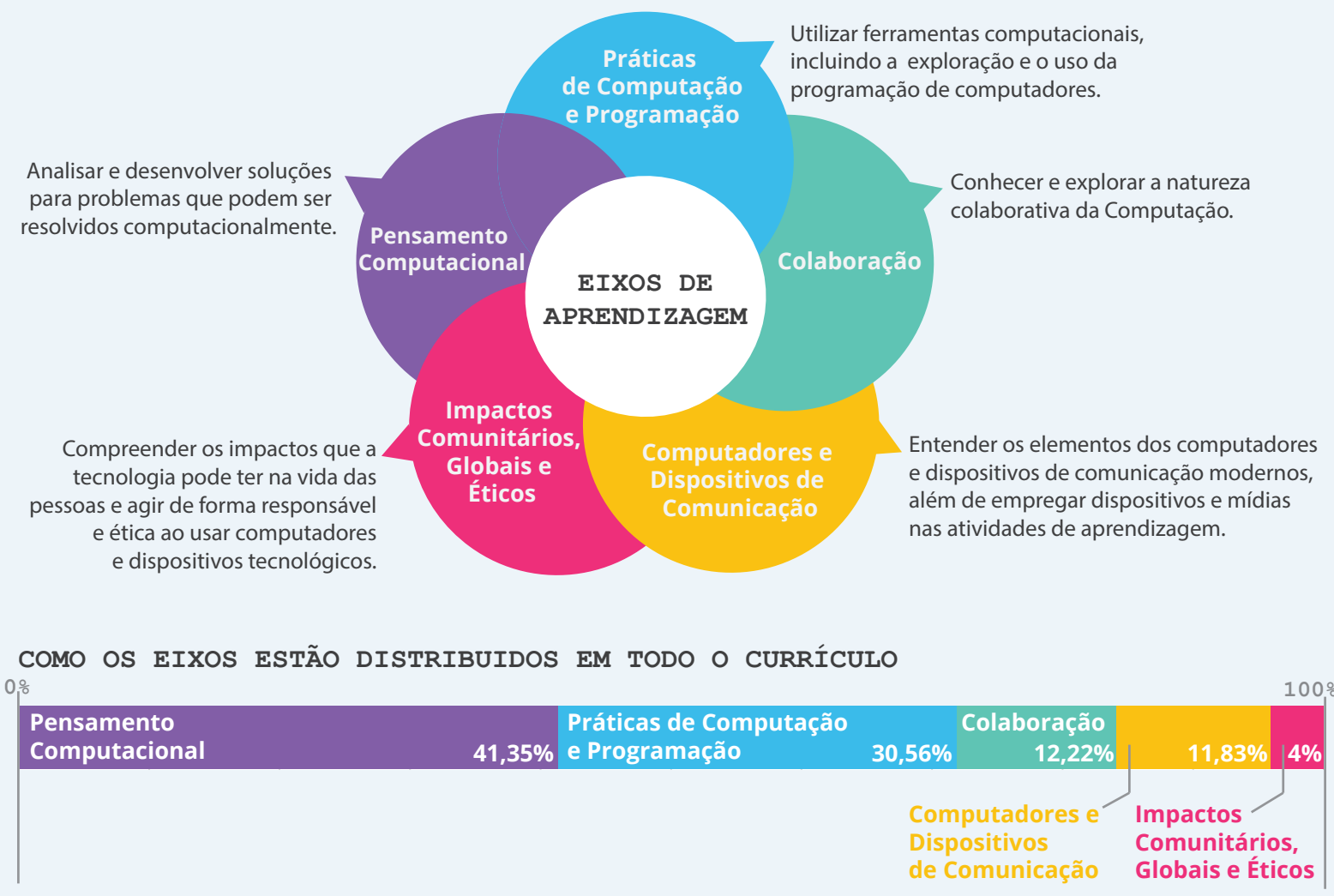

\section{COMO OS EIXOS ESTÃO DISTRIBUIDOS EM CADA ANO}

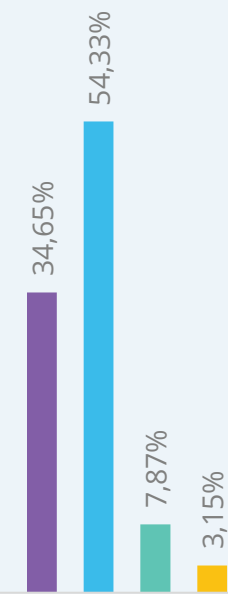

$6^{\circ} \mathrm{ANO}$

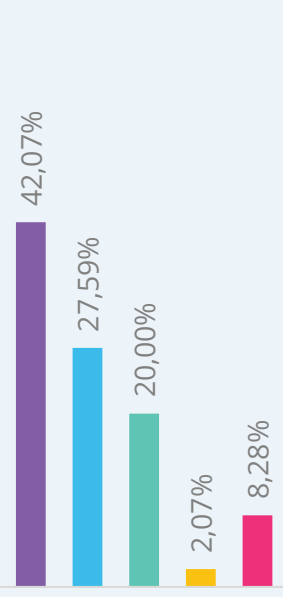

$7^{\circ} \mathrm{ANO}$

- Pensamento Computacional

- Colaboração

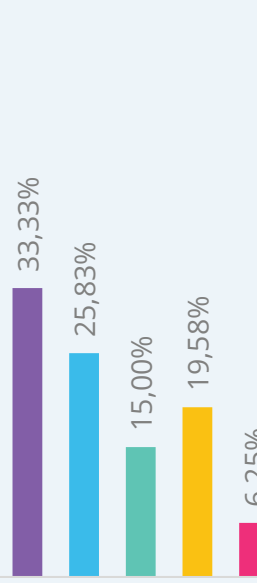

$8^{\circ} \mathrm{ANO}$

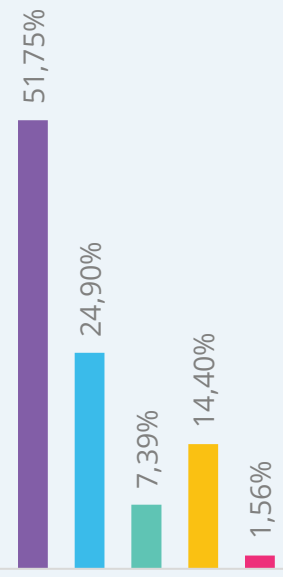

$9^{\circ} \mathrm{ANO}$

- Práticas de Computação e Programação

- Computadores e Dispositivos de Comunicação

- Impactos Comunitários, Globais e Éticos

Figura 1: Eixos de aprendizagem do currículo Computação Fundamental. 
O eixo Práticas de Computação e Programação (PCP) está pautado no uso das ferramentas computacionais e da programação de computadores. Dentre as competências que são trabalhadas, estão o uso de aplicativos e da programação de computadores para apoiar a própria aprendizagem, a expressão e a resolução de problemas. Também é propósito deste eixo que os estudantes entendam a ampla gama de oportunidades que os conhecimentos em computação podem oferecer, como identificar carreiras interdisciplinares que são aprimoradas pela ciência da computação.

O eixo Colaboração (C) parte da ideia de que a Computação é uma disciplina intrinsecamente colaborativa uma vez que grandes avanços na área dificilmente são alcançados de maneira individual. Neste sentido, os estudantes participam de atividades colaborativas para resolução de problemas, como programação em pares, uso de ferramentas online e sistemas colaborativos.

O Eixo Computadores e Dispositivos de Comunicação (CDC) tem como principal objetivo compreender os elementos dos computadores, dispositivos de comunicação e redes de computadores. Assim, os estudantes aprendem sobre equipamentos e dispositivos que podem auxiliá-los em suas atividades de aprendizagem e aos componentes que compõem os computadores e as redes de computadores.

O eixo Impactos Comunitários, Globais e Éticos (ICGE) considera os princípios de agir de forma responsável e ética ao usar os computadores, tanto de forma independente quanto com outras pessoas. Assim, os estudantes aprendem princípios de privacidade pessoal, segurança, direitos autorais e comportamentos adequados e inadequados nas redes sociais. Adicionalmente, os estudantes também devem entender o papel da tecnologia na vida das pessoas, como elas impactam a cultura na qual estão inseridas e como a distribuição de recursos de computação em uma economia global levanta questões de equidade, acesso e poder.

A Figura 1 apresenta uma visão geral do impacto cada eixo ao longo dos quatro anos do currículo. Os eixos PC e PCP recebem maior destaque em todos os anos porque trabalhamos o uso das ferramentas computacionais, em especial as que permitem programar computadores, como um meio de auxiliá-los nas atividades do cotidiano e como um meio de comunicação e expressão. Em todos os anos do currículo, as atividades são elaboradas para proporcionar aos estudantes a visão de que eles são capazes não apenas de entender a tecnologia a seu redor, mas também de criar artefatos tecnológicos para a resolução de problemas e para a autoexpressão. Os demais eixos são trabalhados de maneira transversal, e recebem destaque ao longo do currículo em momentos oportunos. O eixo ICGE não é trabalhado no primeiro livro (sexto ano).

Definimos dois conjuntos de objetivos de aprendizagem dentro de nosso currículo: um voltado para a proposta inicial para o sexto ano e outro para as séries posteriores. Esta divisão foi realizada seguindo os dois primeiros níveis do currículo da CSTA: Ciência da Computação e Eu (sexto ano) e Ciência da Computação e Comunidade (sétimo, oitavo e nono anos). Embora o nível Ciência da Computação e Eu seja mais voltado para a Educação Infantil e o Ensino Fundamental I, nosso currículo decidiu explicitamente não depender de formação prévia nestes anos. Por isso, adaptamos os objetivos do primeiro nível para o início do nosso currículo, no sexto ano, de modo a contemplar os fundamentos introdutórios necessários da computação.

A Figura 2 exibe a lista de resultados de aprendizagem esperados para a proposta do sexto ano. Na primeira série contemplada pelo nosso currículo propomos uma introdução despreocupada ao uso do computador e ao universo da programação. Neste contexto, definimos um conjunto menor de resultados de aprendizagem que trabalha os eixos de PC, PCP, C e CDC. A Figura 3 


\section{OBJETIVOS DE APRENDIZAGEM - $6^{\circ}$ ANO}

\section{Pensamento Computacional}

PC1. Usar recursos tecnológicos para resolver problemas adequados.

PC2. Usar ferramentas de escrita, câmeras digitais e ferramentas de desenho para ilustrar pensamentos, ideias e histórias com passo a passo. PC3. Entender como classificar informações sem usar um computador.

PC4. Reconhecer que o software é criado para controlar as operações do computador.

PC5. Demonstrar como 0s e 1s podem ser usados para representar informações.

PC6. Entender e utilizar as etapas básicas na resolução algorítmica de problemas.

PC7. Desenvolver um entendimento simples de um algoritmo usando exercícios sem computador.

PC8. Demonstrar como uma sequência de bits pode ser usada para representar informações alfanuméricas.

PC9. Fazer uma lista de subproblemas a considerar ao abordar um problema maior.

PC10. Compreender as conexões entre ciência da computação e outros campos.

\section{Práticas de Computação e Programação}

PCP1. Usar recursos tecnológicos para realizar pesquisas apropriadas.

PCP2. Criar produtos multimídia com o apoio de professores, membros da família ou parceiros estudantis.

PCP3. Construir um conjunto de instruções para realizar uma tarefa simples.

PCP4. Identificar trabalhos que usam computação e tecnologia.

PCP5. Usar ferramentas de tecnologia para atividades de redação, comunicação e publicação individuais.

PCP6. Construir um programa como um conjunto de instruções passo a passo para ser encenado.

PCP7. Implementar soluções de problemas usando uma linguagem de programação visual baseada em blocos.

PCP8. Navegar entre páginas da Web usando hiperlinks e conduzir pesquisas simples usando mecanismos de pesquisa.

PCP9. Identificar uma ampla gama de trabalhos que exigem conhecimento ou uso de computação.

\section{Colaboração}

C1. Trabalhar de forma cooperativa e colaborativa com colegas, professores e outros que usam tecnologia.

C2. Usar ferramentas de tecnologia de produtividade.

C3. Identificar maneiras pelas quais o trabalho em equipe e a colaboração podem apoiar a solução de problemas e a inovação.

\section{Computadores e Dispositivos de Comunicação}

CDC1. Demonstrar um nível apropriado de proficiência na utilização de dispositivos de entrada e saída padrão, para operar com sucesso computadores e tecnologias relacionadas.

CDC2. Compreender a difusão dos computadores e computação na vida diária.

CDC3. Aplicar estratégias para identificar problemas simples de hardware e software que possam ocorrer durante o uso.

CDC4. Identifique os fatores que distinguem os seres humanos das máquinas.

Figura 2: Objetivos de aprendizagem empregados na proposta Computação e Eu, para o sexto ano.

exibe os resultados de aprendizagem definidos para o sétimo, oitavo e nono anos, selecionados a partir do segundo nível do currículo da CSTA. Para estas séries, os cinco eixos do currículo são trabalhados.

Os objetivos de aprendizagem definidos são trabalhados em nosso currículo através de unidades temáticas de ensino. Cada série possui uma proposta diferente, com quatro unidades temáticas. A Figura 4 exibe as capas dos livros de cada série e suas respectivas unidades temáticas. Cada unidade de aprendizagem trabalha, dentro de um contexto motivacional específico, conceitos e habilidades necessários para atender aos objetivos de aprendizagem do currículo. Alguns dos objetivos de aprendizagem são trabalhados mais de uma vez em aulas diferentes dentro de uma mesma série ou em anos diferentes. Esta repetição reflete a natureza em espiral de nosso currículo, que trabalha um mesmo conceito em contextos motivacionais diferentes. As unidades temáticas foram elaboradas para fomentar a aprendizagem significativa e em espiral dos conceitos e habilidades. Nas subseções a seguir, descrevemos em detalhes a proposta para cada ano, os requisitos para a implementação do currículo e suas possibilidades, e a relação entre nosso currículo e a Base Nacional Comum Curricular (BNCC). 


\section{OBJETIVOS DE APRENDIZAGEM - $7^{\circ}$ ao $9^{\circ}$ ANOS}

\section{Pensamento Computacional}

PC1. Descrever como uma simulação pode ser usada para resolver um problema.

PC2. Usar passos básicos na solução de problemas algorítmicos para projetar soluções.

PC3. Descrever o processo de paralelização no que se refere à solução de problemas.

PC4. Definir um algoritmo como uma sequência de instruções que pode ser processada por um computador.

PC5. Avaliar maneiras pelas quais diferentes algoritmos podem ser usados para resolver o mesmo problema.

PC6. Trabalhar com algoritmos de busca e classificação.

PC7. Descrever e analisar uma sequência de instruç̃̃es que estão sendo seguidas.

PC8. Representar dados de várias formas, incluindo texto, sons, imagens e números.

PC9. Usar representações visuais de estados de problemas, estruturas e dados.

PC10. Interagir com modelos e simulações de conteúdo específico para apoiar a aprendizagem e pesquisa.

PC11. Avaliar quais tipos de problemas podem ser resolvidos usando modelagem e simulação.

PC12. Analisar o grau em que um modelo de computador representa com precisão o mundo real.

PC13. Usar abstração para decompor um problema em subproblemas.

PC14. Compreender a noção de hierarquia e abstração na computação, incluindo linguagens de alto nível, tradução, conjunto de instruções, e circuitos lógicos.

PC15. Examinar as conexões entre os elementos da matemática e da ciência da computação, incluindo números binários, lógica, conjuntos e funções.

PC16. Fornecer exemplos de aplicações interdisciplinares do pensamento computacional.

\section{Práticas de Computação e Programação}

PCP3. Usar recursos de tecnologia para a resolução de problemas e o aprendizado auto direcionado.

PCP4. Usar ferramentas de produtividade de finalidade geral e periféricos para apoiar a produtividade pessoal, corrigir déficits de habilidades e facilitar o aprendizado.

PCP5. Reunir e manipular dados usando uma variedade de ferramentas digitais.

PCP6. Usar dispositivos de computação para acessar informaç̃̃es remotas, comunicar-se com outras pessoas e buscar interesses pessoais.

PCP7. Selecionar ferramentas apropriadas e recursos de tecnologia para realizar uma variedade de tarefas e resolver problemas.

PCP8. Usar uma variedade de ferramentas multimídia e periféricos para apoiar a produtividade pessoal e o aprendizado em todo o currículo.

PCP9. Projetar, desenvolver, publicar e apresentar produtos usando recursos de tecnologia que demonstram e comunicam conceitos do currículo.

PCP10. Demonstrar compreensão dos algoritmos e sua aplicação prática.

PCP11. Implementar soluções de problemas usando uma linguagem de programação, incluindo: looping, condicionais, lógica, expressões, variáveis e funções.

PCP12. Demonstrar boas práticas em segurança de informações pessoais, usando senhas, criptografia e transações seguras.

PCP13. Identificar carreiras interdisciplinares que são aprimoradas pela ciência da computação.

PCP14. Demonstrar disposições para a resolução de problemas abertos e programação.

PCP15. Coletar e analisar dados que são produzidos a partir de várias execuções de um programa de computador.

\section{Colaboração}

C1. Coletar informações e comunicar-se eletronicamente com outras pessoas com suporte de professores, membros da família ou parceiros estudantis.

C2. Usar recursos on-line, como ambientes da Web colaborativos.

C3. Usar ferramentas de tecnologia de produtividade para atividades de redação, comunicação e publicação individuais e colaborativas

C4. Usar recursos on-line para participar de atividades colaborativas de solução de problemas com o objetivo de desenvolver soluções ou produtos.

C5. Aplicar ferramentas de produtividade/multimídia e periféricos para a colaboração e apoiar o aprendizado em todo o currículo.

C6. Criar, desenvolver, publicar e apresentar, de forma colaborativa, produtos usando recursos de tecnologia que demonstram e comunicam conceitos do currículo.

C7. Colaborar com colegas, especialistas e outras pessoas usando práticas colaborativas, como programação em pares, trabalho em equipes e participação em atividades de aprendizado ativo em grupo.

C8. Apresentar disposição necessária para colaboração: fornecer feedback útil, integrar feedback, compreender e aceitar múltiplas perspectivas, e trabalhar com socialização.

\section{Computadores e Dispositivos de Comunicacão}

CDC1. Reconhecer que os computadores modelam o comportamento inteligente.

CDC2. Identificar as informações que estão chegando ao computador de várias fontes através de uma rede.

CDC3. Reconhecer que os computadores são dispositivos que executam programas.

CDC4. Identificar uma variedade de dispositivos eletrônicos que contêm processadores computacionais.

CDC5. Demonstrar uma compreensão da relação entre hardware e software.

CDC6. Usar terminologia precisa e adequada ao seu estágio de desenvolvimento ao se comunicar sobre tecnologia.

CDC8. Descrever os principais componentes e funções dos sistemas e redes de computadores.

CDC9. Descrever o que distingue os seres humanos das máquinas, concentrando-se na inteligência humana versus a inteligência das máquinas e nas maneiras pelas quais podemos comunicar.

CDC10. Descrever maneiras pelas quais os computadores usam modelos de comportamento inteligente.

\section{Impactos Comunitários, Globais e Éticos}

ICGE1. Praticar a cidadania digital responsável (comportamentos legais e éticos) no uso de sistemas de tecnologia e software.

ICGE2. Identificar comportamentos sociais e éticos positivos e negativos para o uso da tecnologia.

ICGE3. Discutir questões básicas relacionadas ao uso responsável de tecnologia e informação e as consequências do uso inadequado.

ICGE4. Identificar o impacto da tecnologia (por exemplo, redes sociais, cyberbullying).

ICGE5. Compreender questões éticas relacionadas a computadores (por exemplo, direitos autorais e propriedade intelectual).

ICGE6. Identificar o impacto da tecnologia na vida pessoal e na sociedade.

ICGE7. Avaliar a precisão, relevância, adequação, abrangência e vieses que ocorrem em fontes de informação eletrônica sobre problemas do mundo real.

ICGE8. Compreender e descrever questões éticas relacionadas a computadores e redes.

ICGE9. Expor comportamentos legais e éticos ao usar informações e tecnologia e discutir as consequências do uso indevido.

ICGE10. Demonstrar conhecimento das mudanças nas tecnologias da informação ao longo do tempo e os efeitos que essas mudanças têm sobre a educação, local de trabalho e sociedade.

ICGE11. Analisar os impactos positivos e negativos da computação na cultura humana.

ICGE13. Descrever questões éticas relacionadas a computadores e redes (por exemplo, segurança, privacidade e compartilhamento de informações).

ICGE14. Discutir como a distribuição desigual de recursos de computação em uma economia global levanta questões de equidade, acesso e poder.

Figura 3: Objetivos de aprendizagem empregados nas propostas Computação e Comunidade, Computação e Sociedade e Computação e o Mundo, para o período do sétimo ao nono anos. 


\subsection{Computação e Eu: proposta para o sexto ano}

O programa do sexto ano, intitulado Computação e Eu, promove experiências de ensino-aprendizagem projetadas para que os estudantes percebam a computação como uma ferramenta para a expressão da criatividade, por meio da qual os estudantes podem comunicar seus interesses pessoais e exercitar a criatividade(Santana et al., 2019c). Consideramos que este pode ser o primeiro ano de contato dos estudantes com os computadores do tipo desktop ou notebook e isto se reflete em atividades que envolvem habilidades básicas em tecnologia, como uso do mouse e teclado. As quatro unidades temáticas deste ano promovem a introdução à computação e aos algoritmos, trabalham noções de informática básica, introduzem a computação criativa com Scratch e trabalham a computação criativa com animações.

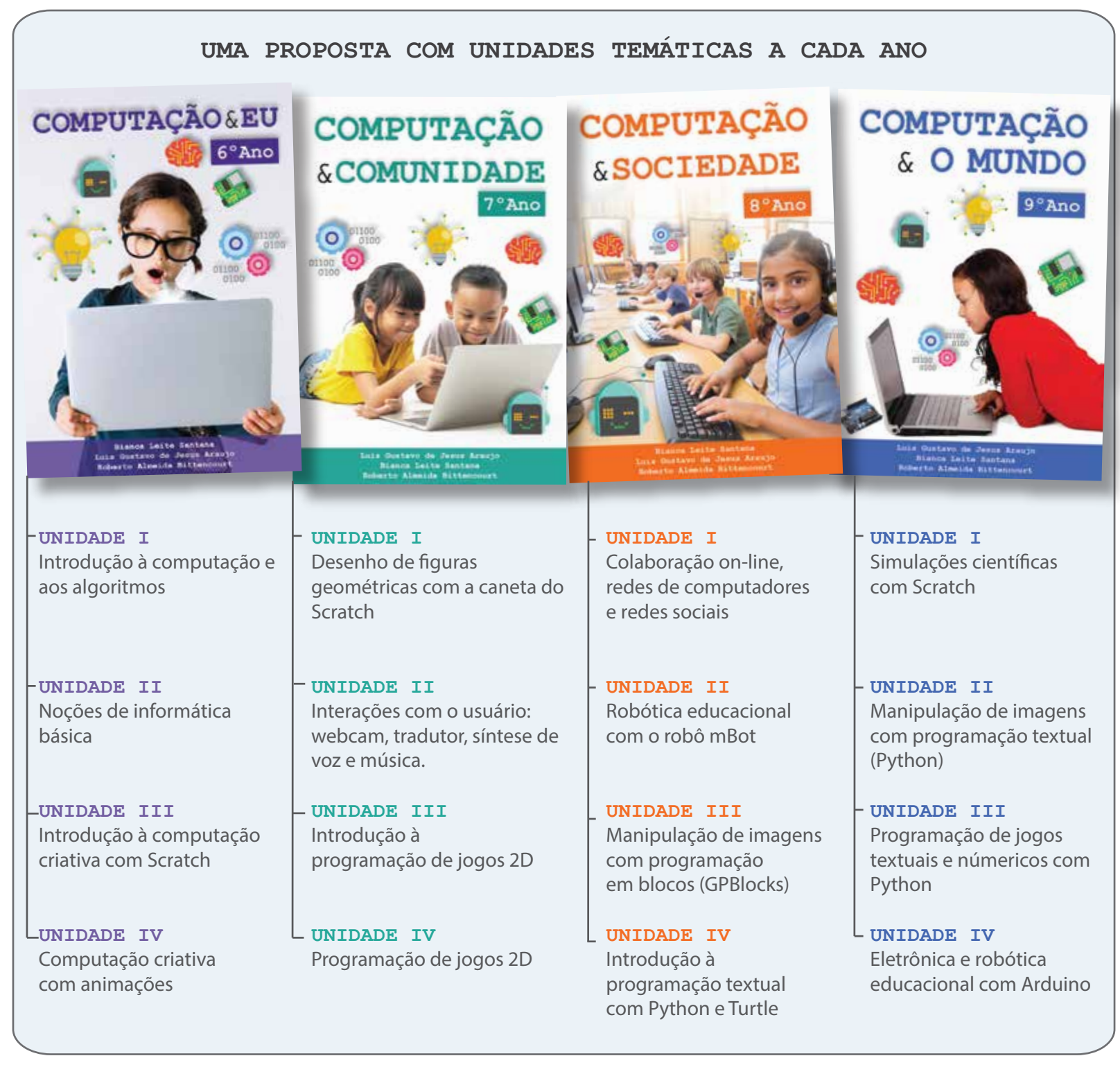

Figura 4: Livros do currículo Computação Fundamental. 
A Unidade I promove uma introdução ao universo da computação, introduzindo os estudantes aos temas da representação binária, das definições de computador e seu funcionamento básico, além de noções de algoritmos. Estes conteúdos são trabalhados principalmente por meio de dinâmicas de computação desplugada, jogos de tabuleiro, e exercícios escritos. Nas aulas que trabalham noções de algoritmos, são trabalhadas sequências, loops e condições através de dinâmicas desplugadas e tutoriais selecionados da iniciativa Code.org ${ }^{3}$.

A Unidade II trabalha noções de informática básica e os estudantes percebem a computação como uma ferramenta útil para o dia a dia, inclusive para as atividades de estudo. As atividades visam promover a melhoria do controle de mouse e teclado, e introduzir o uso de ferramentas de desenho, pesquisa na web, edição de textos e edição de imagens. Adicionalmente, os conhecimentos sobre a computação também são tratados, com abordagens simples sobre álgebra booleana e compressão de textos. Estes conceitos e habilidades são trabalhados por meio do uso do computador, atividades escritas e dinâmicas de computação desplugada.

Nas unidades III e IV, os estudantes são apresentados ao universo da computação criativa com o ambiente Scratch, entendendo a computação e a programação de computadores como um meio para a expressão da criatividade. Neste contexto, são trabalhados conceitos de programação com Scratch, como sequências, loops e condicionais. As aulas destas unidades combinam dinâmicas de computação desplugada, desafios de programação e propostas de projetos práticos de animações.

\subsection{Computação e Comunidade: proposta para o sétimo ano}

O programa do sétimo ano, intitulado Computação e Comunidade, promove experiências de ensino-aprendizagem projetadas para que os estudantes apreciem a presença da computação como um campo relevante e estimulante para a comunicação e a colaboração(Araujo et al., 2019c). Consideramos que os estudantes estão em uma fase em que suas esferas sociais estão crescendo e passam a incorporar mais colegas, professores e outros membros da comunidade. Assim, em comparação com as outras séries, o programa desta série tem mais enfase nos eixos de Colaboração e ICGE. Os objetivos de aprendizagem do eixo de Colaboração fomentam no estudante o senso de que ele vive e trabalha em comunidade. Já os objetivos de aprendizagem do eixo de ICGE procuram fomentar nos estudantes o uso responsável das redes sociais, o respeito aos indivíduos e conhecimentos sobre questões de direitos autorais.

A Unidade I trabalha com desenho de figuras geométricas com a caneta do Scratch. Os estudantes recebem uma série de desafios em cada aula que podem ser resolvidos individualmente ou utilizando programação em pares. Além disto, nesta unidade, os estudantes devem criar seus perfis na comunidade online do Scratch, para disponibilizarem seus projetos de programação. Considerando que os estudantes fazem sua primeira incursão guiada a uma rede social, na última aula desta unidade são promovidas atividades de reflexão sobre o tema de bullying e cyberbullying, evidenciando a responsabilidade dos estudantes em respeitar os indivíduos com quem interagem nas redes sociais.

A Unidade II trabalha a programação com Scratch, com foco no desenvolvimento de programas que envolvem interações com o usuário: webcam, tradutor, síntese de voz e música. Os

\footnotetext{
${ }^{3}$ https://code.org/
} 
estudantes também aprendem sobre a evolução dos computadores e são introduzidos aos temas de busca e inteligência artificial.

As Unidades III e IV aprofundam as habilidades de programação em um contexto de desenvolvimento de jogos 2D com Scratch. Na Unidade III, os estudantes são apresentados ao universo do desenvolvimento de jogos, trabalhando padrões de jogos, como controle pelo teclado e mouse, navegação infinita, criação de fases, implementação de escores de jogador, dentre outros. Nesta unidade, também é trabalhado o conceito de autômatos finitos e as habilidades de criação de apresentações de slides.

A Unidade IV continua as aprendizagens sobre jogos 2D em Scratch, por meio de atividades em que os estudantes criam seus próprios jogos. Ao final do ano, os estudantes desenvolvem um jogo 2D em dupla, obedecendo a uma lista de requisitos mínimos. Esse projeto deve ser disponibilizado on-line e apresentado à comunidade escolar.

\subsection{Computação e Sociedade: proposta para o oitavo ano}

O programa para o oitavo ano, intitulado Computação e Sociedade, considera que os estudantes estão em ampliação constante de suas esferas sociais, além de família e escola. Suas esferas sociais passam a considerar a sociedade mais ampla e suas manifestações por meio das redes sociais on-line (Santana et al., 2020c). As unidades temáticas trabalham os cinco eixos do currículo, considerando esta fase de desenvolvimento dos estudantes. Os resultados de aprendizagem selecionados para este ano são trabalhados por meio de atividades diversas: leituras, exercícios escritos, dinâmicas de computação desplugada, projetos práticos de programação e manipulação de robôs.

A Unidade I trabalha com a colaboração on-line, redes de computadores e redes sociais. Os estudantes criam uma conta Google e trabalham com as ferramentas on-line disponíveis: Google Mail, Drive, Documentos e Apresentações. Nesse processo de uso das ferramentas on-line, a colaboração é trabalhada com dinâmicas envolvendo os colegas da turma. Os estudantes percebem que, com estas ferramentas, podem colaborar e promover projetos com pessoas de outras cidades, estados e até países. As aulas desta unidade também permitem refletir sobre questões éticas relacionadas ao uso das redes sociais e ao compartilhamento on-line de informações.

A Unidade II trabalha a robótica educacional com o robô mBot e o ambiente mBlock, ambos desenvolvidos pela empresa Makeblock ${ }^{4}$. O robô mBot consiste em um carrinho com diversos sensores que pode ser programado por meio do mBlock, ambiente que oferece uma linguagem de programação em blocos bastante similar à do Scratch. Em cada aula, os estudantes exploram uma funcionalidade diferente do robô, como controle de motores DC, buzzer, LEDs, sensor ultrassônico, sensor de luminosidade e controle remoto IR.

A Unidade III apresenta aos estudantes aspectos essenciais da manipulação de imagens por meio da ferramenta GP Blocks. Os estudantes podem aprofundar suas habilidades de pensamento computacional e programação, explorando o desenvolvimento de filtros de imagens. Podem ainda compreender como um computador representa e armazena uma imagem e como manipular os pixels de imagens para promover efeitos visuais como preto e branco e chroma key.

A Unidade IV promove uma introdução à programação textual com a linguagem Python e

\footnotetext{
${ }^{4}$ https://www.makeblock.com
} 
a biblioteca turtle. Os estudantes reveem, com a linguagem Python, o contexto de desenho de figuras geométricas, trabalhado no programa do sétimo ano com a programação em blocos de Scratch. Nesta abordagem, utilizamos explicitamente um contexto já conhecido pelos estudantes para apresentá-los a uma nova maneira de programar os computadores, enfatizando como esta nova maneira de programar se aproxima do que os programadores profissionais fazem. São trabalhados, de maneira individual ou em pares, os conceitos de sequência, loops, condicionais e funções.

\subsection{Computação e o Mundo: proposta para o nono ano}

No programa do nono ano, intitulado Computação e o Mundo, procuramos conectar os conhecimentos dos estudantes sobre a computação com o mundo em que vivem, além de trabalhar a resolução de problemas por meio do desenvolvimento de software ou de hardware (Araujo et al., 2020c). Os objetivos de aprendizagem selecionados para este ano são trabalhados por meio de atividades diversas: leituras, exercícios escritos, dinâmicas de computação desplugada, rodas de discussão, projetos práticos envolvendo a montagem de circuitos eletrônicos e/ou programação.

A Unidade I traz o tema das simulações científicas com Scratch. Os estudantes empregam os conhecimentos e habilidades de pensamento computacional e programação que aprenderam ao longo dos anos anteriores para desenvolver programas que representam expressões matemáticas e culminam em simulações de fenômenos físicos ou químicos. Nas aulas, os estudantes estudam e desenvolvem simulações sobre o movimento uniformemente variado, modelos atômicos, sistema solar, dentre outros fenômenos das ciências naturais. Ao final da unidade, os estudantes escolhem um fenômeno de seu interesse e estudam e desenvolvem, por conta própria, a implementação de uma simulação correspondente.

A Unidade II trabalha a manipulação de imagens com a linguagem de programação Python. Utilizamos o ambiente de desenvolvimento $\mathrm{JES}^{5}$, que provê nativamente uma série de funções que auxiliam na manipulação de mídias. Assim, os estudantes fortalecem suas habilidades de programação em Python, por meio da programação de filtros de imagens, já conhecidos dos estudantes. Ao final da unidade, os estudantes desenvolvem um projeto Gerador de Memes, onde criam efeitos próprios.

A Unidade III tem como tema a programação de jogos textuais e numéricos em Python. Os estudantes aprendem sobre criação de fluxogramas para representar algoritmos e implementam enquetes digitais, programas de criptografia, jogo da velha e jogo da forca, dentre outros. Os desafios de programação propostos nesta unidade envolvem a entrada e saída de dados alfanumérica, conceitos de tipos de variáveis, expressões lógicas e aritméticas, estruturas de dados simples e a manipulação de strings. Estes desafios são trabalhados individualmente ou por meio da programação em pares.

A Unidade IV trabalha a eletrônica e a robótica educacional com a plataforma Arduino. Os estudantes montam os circuitos com Arduino e outros componentes, e os programam através da programação em blocos, usando a ferramenta mBlock, a mesma empregada na abordagem com robótica para o oitavo ano. Para desenvolver os projetos, os estudantes estudam os componentes comumente empregados na prototipagem de dispositivos envolvendo a placa Arduino, como pro-

\footnotetext{
${ }^{5}$ http://coweb.cc.gatech.edu/mediaComp-teach
} 
toboard, LEDs, botões e sensores, dentre outros. Ao final desta unidade, os estudantes recebem o desafio de desenvolver e apresentar um protótipo próprio, empregando os componentes estudados.

\subsection{Implementação do Currículo}

Para a implementação integral de nosso currículo, o ideal é que Computação seja tratada como uma área de conhecimento específica, com um componente curricular dedicado a ela. O programa para cada ano prevê um total de 30 aulas, divididas em quatro unidades temáticas de aprendizagem. Cada aula foi projetada para demandar uma carga horária de duas horas-aula semanais, que pode ser cumprida de maneira conjugada ou em dois momentos distintos ao longo da semana, com uma hora-aula cada. Assim, para cumprir integralmente todas as atividades propostas em cada ano do currículo, pode ser necessário reservar uma carga horária anual mínima de 60 horas-aula.

A infraestrutura demandada para a implementação do currículo pode ser adaptada de acordo com a realidade da escola. O ideal é que as aulas que façam uso do computador e de kits de robótica e eletrônica em ambiente reservado, como um laboratório de informática ou espaço maker. Neste espaço, também se faz necessária uma infraestrutura de rede que permita o acesso à internet. Além disso, também recomendamos que seja disponibilizado um computador por estudante ou que uma máquina não seja dividida por mais de dois estudantes, exceto quando isto se fizer necessário pela própria dinâmica da aula. Também recomendamos que, nas aulas com as temáticas da robótica e eletrônica, os kits não sejam divididos por grupos com mais de quatro integrantes. A maioria dos softwares e ferramentas utilizadas possuem licença de uso gratuito. Nos casos em que fazemos menção a uma ferramenta de licença fechada, como o caso dos softwares Microsoft Word e Microsoft PowerPoint, oferecemos em nossos materiais orientações alternativas que consideram o uso de softwares livres equivalentes do pacote Libre Office. Em nossos materiais, sugerimos uma série de dinâmicas de computação desplugada que exigem a impressão e montagem de materiais. Além disso, cada estudante deve receber um cópia completa ou parcial do livro do estudante para que possam acessar as leituras, as atividades em sala e os exercícios para casa, dentre outras atividades propostas.

Considerando a formação requerida dos docentes para que possam realizar as práticas sugeridas, são necessários conhecimentos básicos sobre computação. Os docentes capacitados para aplicar o currículo em todas as séries contempladas devem ter noções de informática básica, redes de computadores, algoritmos, programação em blocos, programação em Python, eletrônica básica e robótica educacional com Arduino. Como estes conhecimentos são abordados em um nível introdutório, consideramos que a proposta pode ser aplicada por professores de outras áreas de conhecimento, desde que passem por um processo de capacitação adequado.

Apesar de fazermos recomendações sobre os formatos ideais de aplicação do currículo, os materiais disponibilizados oferecem a gestores e professores a orientação e a liberdade para aplicação de práticas que ajudem os estudantes a desenvolver as competências e habilidades que culminem nos objetivos de aprendizagem listados. Nosso currículo pode ser adotado de maneira gradual, incluindo computação inicialmente no sexto ano e ampliando a cada ano, Com isso, pode-se adquirir gradualmente a infraestrutura demandada, à medida que for necessário. Além disto, nossa proposta pode ser adaptada para uma abordagem que considere apenas uma hora-aula semanal, ou para uma abordagem de educação integral. Finalmente, apesar de nosso currículo estar fundamentado na ideia de que Computação é uma área do conhecimento específica com 
um componente curricular destacado no currículo escolar, professores e gestores podem fazer a seleção de conteúdos e contextos que podem ser aplicados de maneira transversal com as outras áreas do conhecimento.

\subsection{O currículo Computação Fundamental e a Base Nacional Comum Curricular}

\section{COMPETÊNCIAS DA BNCC E O CURRÍCULO COMPUTAÇÃO FUNTAMENTAL}

\section{Competências Gerais}

1. Valorizar e utilizar os conhecimentos historicamente construídos sobre o mundo físico, social, cultural e digital para entender e explicar a realidade, continuar aprendendo e colaborar para a construção de uma sociedade justa, democrática e inclusiva.

2. Exercitar a curiosidade intelectual e recorrer à abordagem própria das ciências, incluindo a investigação, a reflexão, a análise crítica, a imaginação e a criatividade, para investigar causas, elaborar e testar hipóteses, formular e resolver problemas e criar soluções (inclusive tecnológicas) com base nos conhecimentos das diferentes áreas.

4. Utilizar diferentes linguagens - verbal (oral ou visual-motora, como Libras, e escrita), corporal, visual, sonora e digital -, bem como conhecimentos das linguagens artística, matemática e científica, para se expressar e partilhar informações, experiências, ideias e sentimentos em diferentes contextos e produzir sentidos que levem ao entendimento mútuo.

5. Compreender, utilizar e criar tecnologias digitais de informação e comunicação de forma crítica, significativa, reflexiva e ética nas diversas práticas sociais (incluindo as escolares) para se comunicar, acessar e disseminar informações, produzir conhecimentos, resolver problemas e exercer protagonismo e autoria na vida pessoal e coletiva.

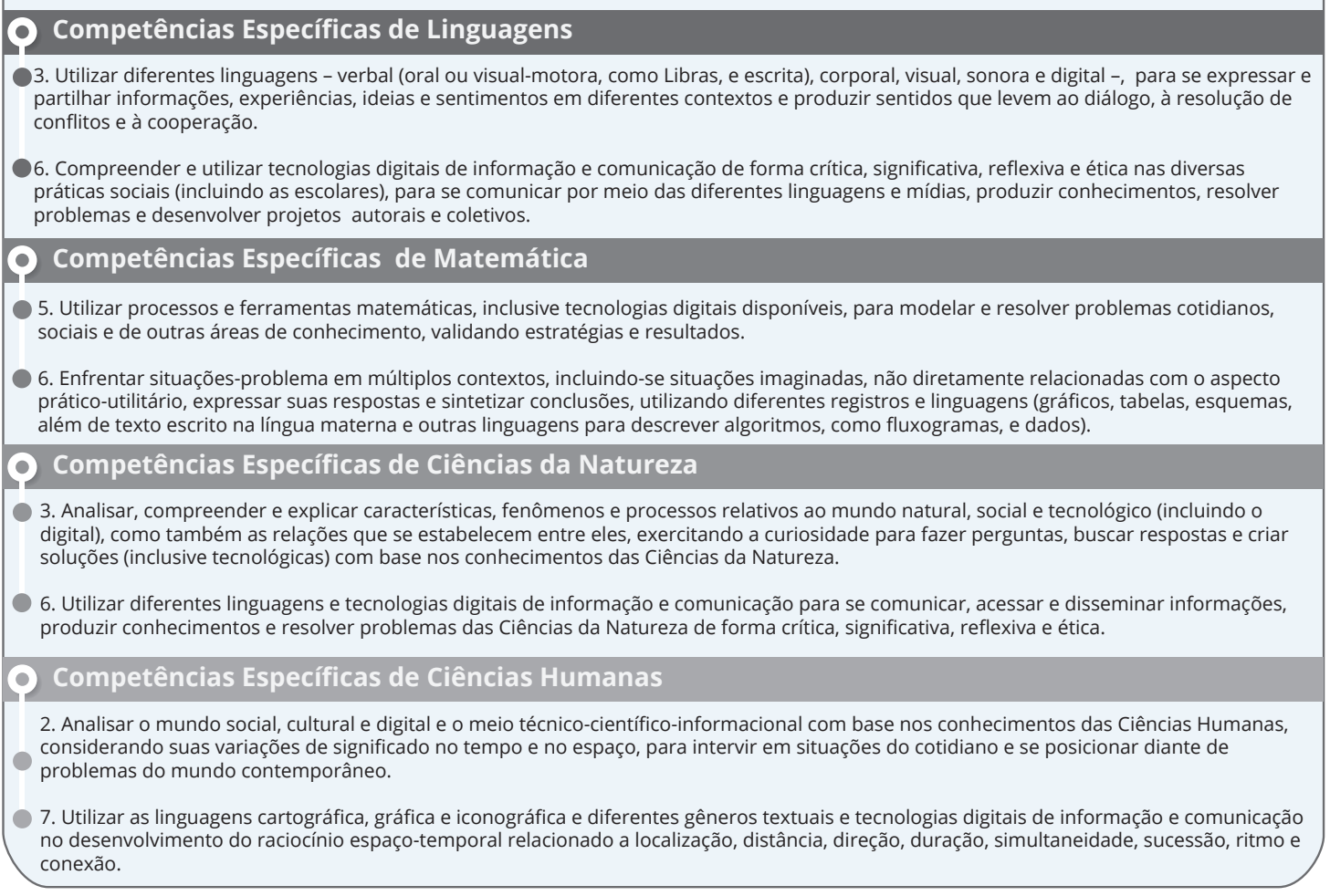

Figura 5: Competências da BNCC com as quais o currículo Computação Fundamental se relaciona.

Apesar de não estabelecermos um alinhamento direto de nosso currículo com as habilidades descritas para os anos finais do ensino fundamental na Base Nacional Comum Curricular (BNCC), é importante esclarecer como o currículo dialoga com estes referenciais curriculares. A Figura 5 lista as competências gerais e específicas para o ensino fundamental da BNCC com as quais o currículo Computação Fundamental se relaciona. 
A BNCC define dez competências gerais que devem ter seu desenvolvimento assegurado aos estudantes ao longo da educação básica (Brasil/MEC, 2018). Considerando as competências gerais, todos os eixos de nosso currículo relacionam-se diretamente com a Competência Geral 5. A Competência Geral 1 relaciona-se com alguns dos objetivos de aprendizagem listados para o eixo de ICGE. As Competências Gerais 2 e 4 relacionam-se com os eixos PC e PCP.

A BNCC não define computação ou tecnologia como um componente curricular explícito nas áreas de conhecimento estabelecidas. Relacionando nosso trabalho com a organização da BNCC para os anos finais do ensino fundamental, destacamos que nosso currículo considera que os estudantes desta etapa estão em uma transição entre a infância e adolescência, marcada por mudanças biológicas, psicológicas, sociais e emocionais. Neste contexto, a chamada cultura digital tem um papel importante, uma vez que os jovens são e estão recorrentemente inseridos no contexto de tecnologias digitais como celulares, tablets, computadores e afins, além de apresentarem interesse intrínseco pelas relações estabelecidas na cultura digital (Boyd \& Marwick, 2011).

Ao longo de seu texto, a BNCC contempla o desenvolvimento de competências e habilidades relacionadas ao uso crítico e responsável das tecnologias digitais de forma transversal e direcionada. Considerando a etapa do ensino fundamental, muitos dos objetivos de aprendizagem de nosso currículo contribuem com as competências definidas para as áreas de conhecimento específicas. As Competências Específicas de Linguagem 3 e 6 relacionam-se com objetivos de aprendizagem dos eixos PCP, C e ICGE, quando os estudantes criam artefatos para autoexpressão e comunicação, individualmente ou por meio da colaboração, e quando refletem sobre aspectos éticos associados ao uso da tecnologia. As Competências Específicas de Matemática 5 e 6 relacionam-se com os eixos PC e PCP, quando estudantes interagem com a programação em blocos e a programação textual como uma ferramenta para a resolução de problemas. As Competências Específicas de Ciências da Natureza 3 e 6 relacionam-se com os eixos de aprendizagem PC, CDC e ICGE, quando os estudantes implementam simulações cientificas, descobrem como a criação de dispositivos tecnológicos, robótica e inteligência artificial é inspirada pela natureza, dentre outras atividades que são propostas ao longo do currículo. As Competências Específicas de Ciências Humanas 2 e 7 relacionam-se com os eixos ICGE, CDC e PC, quando os estudantes discutem sobre o impacto da tecnologia na sociedade e em suas próprias vidas e quando aprendem questões sobre redes de comunicação e Internet, dentre outras atividades.

Estabelecer uma relação direta entre os objetivos de aprendizagem detalhados nos eixos de nosso currículo e as habilidades listadas na BNCC constitui uma das direções de trabalhos futuros em nossa proposta de currículo.

\section{Livros e Materiais Didáticos}

Acreditamos que os livros didáticos e materiais de apoio elaborados consistem no grande diferencial de nosso currículo. Todos os materiais foram elaborados para manter a consistência com os objetivos de aprendizagem selecionados para cada série. Em cada série, há duas versões de livros: uma voltada para professores e outra que pode ser distribuída entre os estudantes. Estes livros possuem o mesmo padrão e organização em todas as séries.

A versão para professores oferece um guia completo para os docentes que conduzam as aulas da proposta curricular. Há um capítulo inicial dedicado à apresentação da proposta e dos 
eixos de aprendizagem que norteiam a série a que se refere o livro. Em sequência, há um capítulo dedicado à apresentação das aulas e seus respectivos conteúdos de maneira resumida. O restante do livro é dedicado à descrição detalhada das aulas, com os materiais e práticas necessárias.

Cada aula possui seu próprio plano de aula, que descreve resumidamente em sua primeira página: 1) o resumo do tema da aula; 2) as habilidades a serem desenvolvidas no decorrer da aula; 3) os conteúdos a serem trabalhados durante a aula; 4) as atividades a serem realizadas durante a aula e/ou como tarefa para casa; 5) os objetivos de aprendizagem para a aula (denominados, nos livros, de resultados de aprendizagem esperados), considerando os eixos de aprendizagem que norteiam a proposta; e 6) os materiais a serem utilizados na aula, incluindo links para materiais externos.

A partir da segunda página de cada aula, estão descritas sugestões para o desenvolvimento da aula, com um passo-a-passo que descreve como os conteúdos podem ser apresentados, como as atividades podem ser desenvolvidas e como os materiais de apoio podem ser empregados (e.g., slides, dinâmicas desplugadas, jogos, músicas, figuras, links externos).

Algumas aulas, especialmente as que possuem uma carga maior de novos conteúdos, podem ter uma seção intitulada Tópicos Relevantes, que descreve brevemente alguns dos conceitos empregados na aula e que deve apoiar os estudantes durante a execução de suas atividades. As aulas que possuem atividades a serem respondidas ou um guia escrito para atividades práticas possuem uma seção intitulada Folha de Atividades. As aulas que possuem propostas de atividades extra-classe possuem uma seção intitulada Tarefa para Casa.

O livro do estudante é essencialmente um workbook que compila as seções de Tópicos Relevantes, Folha de Atividades e Tarefa para Casa de cada aula, quando estas seções existem. Além disto, a versão do estudante possui espaço reservado para o Diário de Bordo, que consiste em um relato livre do estudante a respeito da sua experiência de aprendizagem em cada aula. Os professores podem usar estes diários para compreender o que os estudantes consideram que aprenderam, como eles avaliam a experiência de aprendizagem oferecida e quais as dificuldades enfrentadas.

Nossa proposta de computação como um componente curricular específico não destaca explicitamente a realização atividades de avaliação separadas. Deste modo, os professores ficam livres para avaliar o desempenho dos estudantes do modo como acharem mais adequado, seja pela análise dos projetos desenvolvidos pelos estudantes, seja por avaliações escritas, dentre várias possibilidades. Os professores podem ainda usar os diários de bordo escritos pelos estudantes como medida do engajamento da turma e para o aprimoramento das estratégias de ensino-aprendizagem empregadas. Neste sentido, os estudantes devem ser incentivados a escreverem os seus diários de bordo como um exercício extra-classe regular entre as aulas de Computação.

Desenvolvemos um site de apoio para a proposta Computação Fundamental ${ }^{6}$. Todos os livros que compõem a proposta estão disponíveis para download gratuito através do site de apoio. Também são disponibilizados os materiais a serem impressos para algumas das dinâmicas desplugadas, apresentações de slides para os professores, além de mídias e programas-base para os projetos no computador. A Figura 6 ilustra alguns dos materiais disponíveis para utilizar em dinâmicas de computação. Foram desenvolvidos playsets para imprimir e montar jogos de tabuleiro,

\footnotetext{
${ }^{6}$ https://sites.google.com/view/computacaofundamental/
} 


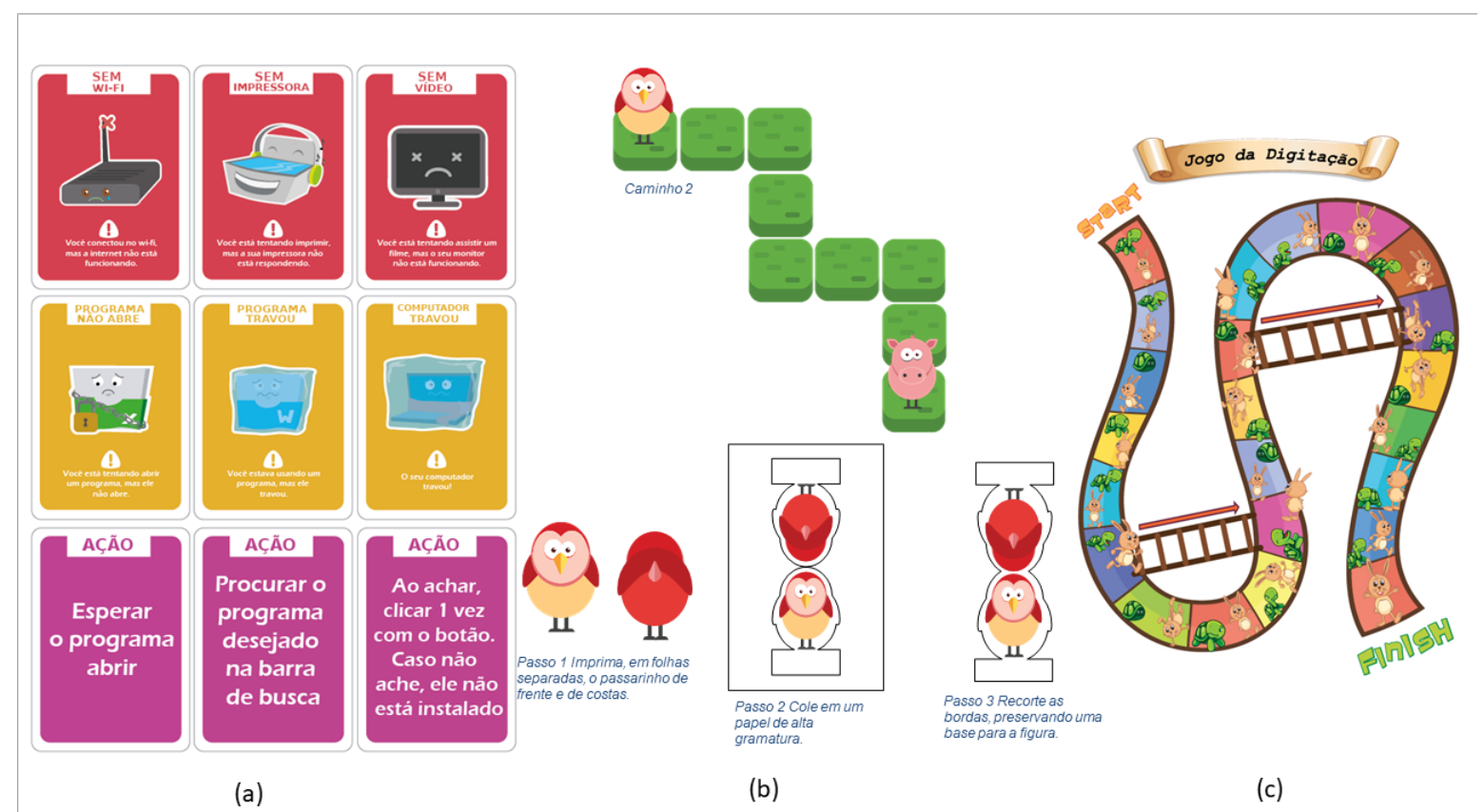

Figura 6: Materiais disponíveis para dinâmicas durante as aulas: (a) Jogo de cartas para resolver problemas com o computador; (b) Playset para dinâmica com algoritmos; (c) Jogo de tabuleiro para dinâmica envolvendo digitação de texto..

jogos de cartas, dentre outras atividades.

\section{Experiências na Educação Básica}

Nesta seção, apresentamos as experiências desenvolvidas com o objetivo de avaliar, de modo preliminar e qualitativo, os livros e os materiais criados. Nossas experiências foram moldadas de acordo com a disponibilidade de professores, turmas e escolas. Assim, foi necessário selecionar unidades específicas dos livros para a avaliação, o que impossibilitou a avaliação dos materiais em sua totalidade. Além disto, nem sempre foi possível avaliar os materiais nas etapas educacionais para as quais os livros foram projetados, embora buscamos aplicá-los em anos próximos aos ideais.

$\mathrm{Na}$ maioria das experiências, as aulas foram divididas em dois momentos. No primeiro momento, o professor discutia alguns conceitos, projetando slides e/ou exemplos no computador. No segundo momento, os estudantes aplicavam os conceitos através de atividades práticas. As atividades eram geralmente guiadas por algum desafio. Adicionalmente, neste momento, buscavase estimular a criatividade através de atividades livres no contexto das aulas em questão. Outras atividades tinham um roteiro próprio seguido pelos estudantes a partir dos materiais do livro, como no caso de atividades desplugadas.

\subsection{Experiência com o Livro I - Sexto Ano}

Os materiais das Unidades I e II do livro do sexto ano foram utilizamos em uma experiência com alunos do sexto ano de uma escola pública estadual. Foram realizadas nove aulas de 50 minutos. Um total de 40 estudantes participou da experiência realizada semanalmente. Um estudante de 
Engenharia de Computação liderou as atividades, acompanhado pelo professor de Matemática da escola.

No primeiro dia, a atividade desenvolvida consistiu em discussões com os estudantes sobre computadores e números binários, além de uma atividade desplugada. No segundo dia, foi abordado o conteúdo de representação de imagens, fazendo relação com os números binários vistos na aula anterior. Os estudantes realizaram uma atividade desplugada sobre pixels. Na terceira aula, os estudantes fizeram uma apresentação de teatro simulando o funcionamento do computador. Cada aluno representou o papel de um componente do computador (entrada, saída, armazenamento/processamento).

Os estudantes utilizaram um jogo de tabuleiro sobre defeitos relacionados ao computador e ações para sua resolução na quarta aula. No jogo, os estudantes precisaram utilizar cartas do tipo Solução para resolver problemas apresentados pelas cartas do tipo Defeitos, divididas em hardware e software. Na quinta aula, os estudantes foram apresentados ao conceito de algoritmo. Como atividade, eles utilizaram peças físicas para percorrer caminhos utilizando blocos similares aos de Scratch. Na sexta aula, uma atividade similar foi realizada com adição do conceito de loops.

Na sétima aula, os estudantes foram apresentados ao conceito de bug, curiosidades sobre este termo e estratégias de identificação com base nos materiais da aula anterior. Na aula seguinte, os estudantes trabalharam com reconhecimento de padrões em palavras e compactação de informação. Por fim, no último dia, os estudantes realizaram uma atividade desplugada sobre comunicação.

Essa experiência possibilitou perceber a adequação dos materiais para trabalhar tópicos iniciais do mundo da computação. Os estudantes se mostraram engajados e participativos. Algumas atividades se mostraram propensas à interdisciplinaridade, como foi o caso do teatro dos números binários e da compactação de informações. O professor titular de Matemática da turma utilizou a atividade do teatro para reforçar o conceito de potenciação após a nossa experiência. Este acontecimento sugere que as atividades possibilitam uma interface ou adequação a outras disciplinas.

\subsection{Experiência com o Livro II - Sétimo Ano}

Assim como o primeiro, o segundo livro da série foi utilizado em uma experiência realizada em uma escola pública estadual. Dez alunos participaram da experiência. As aulas desenvolvidas contemplaram as Unidades I e IV e foram aplicadas em uma turma do segundo ano do ensino médio, sem experiência prévia em programação. Foram realizados sete encontros semanais de três horas cada. Um dos autores deste artigo foi o professor desta disciplina, contando com o auxílio de um estudante de Engenharia da Computação, que atuou como monitor.

$\mathrm{Na}$ primeira aula, os aprendizes foram apresentados ao conceito de algoritmos. Como atividade, eles criaram linhas e quadrados utilizando a caneta do Scratch. Além da caneta, foram discutidos conceitos de movimento e ângulos. Os estudantes demonstraram facilidade ao criar as figuras solicitadas.

$\mathrm{Na}$ segunda aula, os estudantes utilizaram os conceitos aprendidos na aula anterior para a criação de triângulos e estrelas. Percebeu-se que os aprendizes apresentaram maior dificuldade com estas figuras, pois necessitaram trabalhar com ângulos não retos. A estratégia de tentativa e 
erro foi geralmente utilizada, tendo como subsídio o feedback visual de Scratch. No entanto, de modo geral, através do suporte do professor e do monitor, os estudantes conseguiram finalizar as atividades.

No terceiro dia, o professor apresentou estruturas de repetição. Inicialmente, o objetivo foi refatorar os códigos criados anteriormente para a utilização de loops. De modo progressivo, os aprendizes conseguiram perceber a funcionalidade da repetição. Em seguida, foi proposta a criação de figuras com vários quadrados e círculos. Os estudantes entenderam a simplificação do código através de loops, mas perceberam o uso de novos comandos como algo mais complexo. No quarto dia, loops foram usados para criar variações das figuras da aula anterior, alterando cor e espessura da caneta, permitindo exercer a criatividade. Já no quinto dia, foram criadas figuras compostas por várias outras figuras, trabalhando a ideia de modularização.

Finalmente, no sexto e sétimo dias, os estudantes criaram um jogo em Scratch no estilo do jogo clássico Space Invaders, trabalhando conceitos de variáveis, condicionais e loops.

Por meio dessa experiência, percebeu-se que as sequências didáticas propostas estão claras e possibilitam aplicação do material por professores. Além disto, percebeu-se que as atividades estão planejadas e organizadas de modo gradual, minimizando as dificuldades. Os exemplos com figuras geométricas facilitaram a compreensão por conta do feedback visual, e a interface com conceitos matemáticos possibilitou a interdisciplinaridade.

\subsection{Experiência com o Livro III - Oitavo Ano}

Os materiais avaliados do livro do oitavo ano referem-se à Unidade IV. A experiência foi realizada em uma escola pública municipal com uma turma de nono ano. Esta experiência contou com a participação de 28 estudantes. Foram realizadas quatro aulas semanais com duração de uma hora cada. Um dos autores deste artigo foi o professor nesta experiência.

No primeiro encontro, foram apresentadas características da linguagem Python e a ferramenta JES. Nesta aula, os estudantes criaram figuras geométricas (e.g., quadrado, triângulo, pentágono e hexágono). Na aula seguinte, os estudantes fizeram modificações nas atividades desenvolvidas na primeira aula, utilizando funções e experimentando combinações de figuras.

No terceiro dia, os estudantes aprenderam o conceito de loops. A atividade proposta foi a aplicação de loops na criação de figuras mais complexas que as feitas anteriormente. Algumas das modificações permitiram mesclar figuras e aplicar rotações. No quarto dia, os estudantes conheceram as estruturas condicionais. A proposta foi criar variações nas figuras como a mudança de cor das bordas e o seu preenchimento.

Percebeu-se que as sequências didáticas planejadas possibilitaram a aplicação do material de forma simples e direta. Além disto, o conhecimento prévio sobre figuras geométricas e a simplicidade das atividades foram aspectos que facilitaram o entendimento dos conceitos e sua aplicação. É importante salientar que, em uma experiência completa com o livro, os alunos teriam interagido anteriormente com atividades similares com Scratch. Assim, pelo engajamento resultante, consideramos que o material se mostrou adequado aos estudantes. 


\subsection{Experiência com o Livro IV - Nono Ano}

Os materiais da Unidade II do livro do nono ano foram utilizados em uma experiência com alunos do nono ano. Todos os participantes da experiência com os materiais do oitavo ano participaram desta nova experiência. Foram realizados quatro encontros semanais nesta nova etapa.

Nessa experiência, continuamos utilizando a linguagem Python e a ferramenta JES. De modo distinto, aplicamos o contexto de manipulação de imagens. No primeiro dia de aula, os estudantes utilizaram funções básicas do JES para interagir com imagens. Como atividade, os aprendizes criaram imagens, obtiveram valores RGB de pixels e os exibiram no console.

No segundo dia, os estudantes utilizaram loops para interagir com um array de pixels. Como proposta, criaram efeitos de Matiz. No terceiro dia de aula, continuaram utilizando loops e foram apresentados à teoria dos efeitos de Escala de Cinza e Negativo, implementando estas manipulações em Python. Por fim, no quarto dia, os aprendizes foram apresentados às estruturas condicionais e utilizaram este conceito para a criação do efeito Preto e Branco.

Pelo engajamento encontrado, essa experiência apontou que o ambiente JES e o contexto de manipulação de imagens são adequados a esta etapa educacional. Além disto, percebeu-se que estes contextos estimularam a criatividade dos estudantes. O uso de efeitos conhecidos por eles foi um fator motivacional importante e não esteve inversamente relacionado à sua complexidade, já que eles sentiram-se estimulados por atividades desafiadoras. Percebeu-se, da experiência, que os materiais estavam adequados ao nível educacional em que estavam os estudantes.

\section{Discussão}

Nesta seção, discutimos os principais desafios de implantação do currículo Computação Fundamental e benefícios associados ao seu uso. Os principais desafios que surgiram a partir de nossas experiências prévias relacionam-se com a infraestrutura, capacitação de professores, integração curricular e dificuldades dos estudantes com o uso do inglês. Dentre os potenciais benefícios percebidos, destacam-se a computação como uma ferramenta para expressar criatividade, a formação interdisciplinar, além de potenciais motivação e engajamento melhorados e melhor retenção do conhecimento pelo uso explícito das bases teóricas deste currículo.

Infraestrutura. O currículo proposto prevê atividades com uso de diversos recursos. A maioria das atividades práticas envolve o uso de um computador por aluno ou dupla, infraestrutura mínima para iniciar a implantação curricular. $\mathrm{O}$ acesso à internet é necessário em todas as séries, embora seja possível iniciar a implantação do currículo sem ela, fazendo adaptações no sexto ano para trabalhar sem este recurso. Atividades de eletrônica e robótica demandam a aquisição dos kits em quantidade suficiente para dividir a turma em grupos de, no máximo, quatro estudantes. Além disso, cada estudante deve ter uma cópia do livro para que possa fazer as leituras e exercícios. Portanto, há uma estrutura básica demandada, que consiste em um laboratório básico de informática. Os gestores podem adiar a aquisição dos robôs mBot e dos kits de eletrônica, se optarem por uma implementação gradual do currículo, conforme as turmas iniciais avancem. Isto constitui um desafio para a implementação do currículo, que tornou-se evidente em nossa busca por espaços de formação que pudessem ser utilizados para as nossas experiências. A maioria das escolas, principalmente escolas públicas, não dispõem de laboratório de informática equipado 
e/ou recebendo manutenção, o que ressalta a necessidade de articulação para promover melhorias na infraestrutura das escolas.

Capacitação Docente. Nossa proposta aborda conceitos de computação como Pensamento Computacional, Algoritmos, Interação Humano-Computador, Redes de Computadores, Redes Sociais, Robótica e Eletrônica, dentre outros. Assim, faz-se necessário que os professores que utilizem os materiais propostos tenham uma capacitação adequada na área de Computação. De forma ideal, destacamos a figura do Licenciado em Computação por possuir os conhecimentos técnicos necessários, além de conhecimentos da área de Educação necessários para a condução das aulas, atividades e avaliações. No entanto, ressaltamos a possibilidade de capacitar professores de outras áreas que tenham interesse em lecionar computação.

Integração ao currículo escolar. Em nossas experiências, constatamos que algumas escolas utilizam o turno oposto para as disciplinas de informática/computação. Outras escolas, de educação em tempo integral, alocam espaço para atividades de computação pela flexibilidade maior dos currículos da educação integral. Devido ao grande número de disciplinas já existentes, estas podem ser boas soluções para a integração de nossa proposta aos currículos escolares existentes.

Inglês como desafio. Um desafio encontrado em nossas experiências foi a dificuldade com o idioma inglês. Como a nossa abordagem utiliza linguagens de programação textuais, este desafio era esperado. No entanto, aos introduzirmos programação por meio de linguagem de blocos e repetirmos contextos em anos posteriores, é possível reduzir as dificuldades com o inglês por meio de associações. Este desafio também pode ser visto como uma oportunidade de multidisciplinaridade com o componente curricular Inglês.

Expressão, comunicação e criatividade. Devido ao uso de diferentes contextos motivacionais da computação, nosso currículo possibilita o exercício da computação como um meio para expressão pessoal. Assim, enquanto aprendem sobre os temas centrais da computação, os estudantes podem expressar seus pensamentos e sentimentos artisticamente, por meio da criação de mídias digitais como figuras, sons, animações, dentre outras. Além disto, os estudantes também utilizam a computação como um meio de comunicação com seus colegas e com o mundo, uma vez que frequentemente compartilham os artefatos desenvolvidos. Estas atividades oferecem uma nova visão de mundo para os estudantes, empoderando-os como produtores de conteúdo em uma sociedade tecnológica.

Interdisciplinaridade. Embora trabalhemos com conteúdos de computação, foi perceptível que diversas aulas podem ser utilizadas como interface com outras disciplinas. A computação relaciona-se diretamente com as disciplinas STEAM ${ }^{7}$. Artes podem utilizar conceitos como cores e formas e a manipulação de imagens. O componente de Matemática pode utilizar as aulas que trabalham com plano cartesiano e figuras geométricas. As aulas de Ciências podem utilizar a unidade sobre simulação. Diversas integrações são possíveis e outras podem ser descobertas pelos professores e estudantes ao vivenciarem esta proposta curricular.

Motivação, engajamento e retenção do conhecimento. Pelo uso explícito das bases teóricas de currículo em espiral, aprendizagem significativa, projetos construcionistas e computação contextualizada, percebemos, ainda que informalmente, bons níveis de motivação e engajamento pelos estudantes participantes das experiências realizadas. Obviamente, a implantação completa

\footnotetext{
${ }^{7}$ STEAM - Science, Technology, Engineering, Arts and Mathematics.
} 
do currículo em um período de quatro anos pode realçar melhor os benefícios destas escolhas, especialmente através de avaliações in loco em escolas que adotem o currículo. Ainda não é possível falar categoricamente de melhor retenção do conhecimento dada a falta destas experiências de longo prazo. Entretanto, por nossa experiência prévia no uso destes e de outros materiais que deram base a estes livros durante um período de cerca de oito anos de experiências em escolas, acreditamos no potencial deste currículo para a manutenção da motivação e engajamento dos estudantes e para a melhor retenção de conhecimento amparada por bases pedagógicas sólidas.

\section{Trabalhos Relacionados}

Quando o currículo Computação Fundamental foi iniciado, preferimos trabalhar com a versão de 2011 dos referenciais curriculares da CSTA (Seehorn et al., 2011), pois o documento posterior ainda estava em construção, além de ser menos detalhado que a versão de 2011. A versão de 2017 apresenta uma organização um pouco diferente, mantendo os três níveis de ensino, mas dividindoos em subníveis quando apropriado (Computer Science Teachers Association, 2017). Assim, o primeiro nível é dividido nos subníveis $1 \mathrm{~A}$, da educação infantil até o segundo ano (idades de 5 a 7 anos), e 1B, do terceiro ao quinto anos (idades de 8 a 11). O segundo nível não é subdividido e abarca do sexto ao oitavo anos (idades de 11 a 14), período da middle school dos EUA. O terceiro nível, da high school dos EUA, é dividido nos subníveis 3A, do nono e décimo anos (idades de 14 a 16), e 3B, do décimo primeiro e décimo segundo anos (idades de 16 a 18). Em 2017, Os eixos do currículo de 2011 foram reorganizados para 1) Sistemas de Computação; 2) Redes e a Internet; 3) Dados e Análise; 4) Algoritmos e Programação; 5) Impactos da Computação, descrevendo objetivos de aprendizagem e subconceitos para cada nível ou subnível de ensino, e conectando-os com um framework de práticas. Diferentes escolhas curriculares levam a diferentes soluções e a solução de 2017 da CSTA ainda deve passar por uma etapa de apropriação pela comunidade.

Talvez uma das iniciativas mais completas e detalhadas de currículos de computação na educação básica seja o do Distrito das Escolas Públicas de Chicago ${ }^{8}$ (CPS, da sigla em inglês) (OCS at CPS, 2021). O CPS é um dos mais ativos membros da coalizão CS4All (CSforAll, 2021) e, como tanto, tem utilizado diversos currículos detalhados de computação para a escola, desde o jardim de infância até o final do ensino médio. Diferente do nosso currículo que apresenta apenas um itinerário formativo, o CPS utiliza vários itinerários formativos baseados em diversos currículos e materiais, como o CSFirst ${ }^{9}$, o Scratch Encore ${ }^{10}$, o Bootstrap ${ }^{11}$, o Action Fractions ${ }^{12}$, o Project GUTS ${ }^{13}$ e o Common Sense Media ${ }^{14}$, para a educação infantil e o ensino fundamental, e os currículos Exploring Computer Science (ECS) ${ }^{15}$, AP Computer Science Principles (CSP) ${ }^{16}$ e Computational Thinking and Problem Solving (CTPS $)^{17}$, para o ensino médio. Em todos os

\footnotetext{
${ }^{8}$ CPS: Chicago Public Schools

${ }^{9} \mathrm{https} / / / \mathrm{csfirst}$.withgoogle.com/c/cs-first/en/curriculum.html

${ }^{10}$ https://www.canonlab.org/scratchencoremodules

${ }^{11} \mathrm{https}: / / \mathrm{www}$.bootstrapworld.org/

${ }^{12} \mathrm{https}$ ://www.canonlab.org/actionfractionslessons

${ }^{13}$ https://teacherswithguts.org/

${ }^{14} \mathrm{https}$ ://www.commonsense.org/education/digital-citizenship/curriculum

${ }^{15} \mathrm{http}: / /$ www.exploringes.org/

${ }^{16} \mathrm{https}$ ://apstudents.collegeboard.org/courses/ap-computer-science-principles

${ }^{17}$ https://sites.google.com/cps.edu/cs4all/for-teachers/high-school/ctps
} 
casos, o CPS oferece guias detalhados para composição de implementações de currículos a partir dos materiais e currículos existentes, além de oferecer planos de aula detalhados.

A iniciativa Computing at School, uma coalizão de indústria, professores e pais de alunos foi lançada em 2008 para incentivar mudanças nos currículos escolares do Reino Unido (Computing at School, 2021). Com a modificação dos currículos, demandando mais rigor no ensino de programação e álgebra booleana, por exemplo, houve dificuldades entre os professores, demandando programas específicos de formação apoiados pelo Ministério da Educação deste país (Fowler \& Vegas, 2021). Estes programas foram realizados a partir da criação do National Centre for Computing Education (NCCE), que produziu materiais didáticos e planos de aula de computação voltados para a educação básica, além de executar os programas de formação de professores para apropriação dos materiais desenvolvidos. Como resultado, o currículo Teach Computing ${ }^{18}$ conta com 500 horas de aulas em 69 unidades planejadas para quatro diferentes níveis de ensino, dos 5 aos 16 anos de idade, com materiais tão variados quanto os utilizados pelo Distrito Escolar de Chicago. As lições aprendidas do programa do NCCE ressaltam como a formação de professores foi fundamental para as mudanças nos currículos escolares de computação do Reino Unido.

Outros países também tem desenvolvido currículos de computação para a educação básica. Alguns países, como Israel, com larga tradição no ensino médio (Hazzan, Gal-Ezer, \& Blum, 2008) e mais recente inserção no Ensino Fundamental II (Bargury et al., 2012), Coreia do Sul (Choi et al., 2015) e Nova Zelândia (Bell, Andreae, \& Lambert, 2010), já possuem uma tradição de longo prazo no assunto com uma larga base de materiais didáticos abertos desenvolvidos, como é o caso do Computer Science Field Guide da Nova Zelândia (Bell, 2013). Outros países possuem uma inserção da computação mais recente, como é o caso da Irlanda (Becker \& Quille, 2020) e da Argentina (López et al., 2019), mas já possuem materiais didáticos de computação para o ensino médio. Alguns trabalhos discutem, de forma descritiva e comparativa, as iniciativas e currículos de computação na educação básica em vários países, oferecendo uma visão ampla, embora datada, devido aos rápidos avanços recentes nesta área (Hubwieser et al., 2015; Szabo et al., 2019).

No Brasil, o currículo do Centro de Inovação para a Educação Brasileira (CIEB) oferece referenciais curriculares para três etapas de ensino: Educação Básica Infantil e Fundamental, Educação Básica Ensino Médio e Educação Profissional Técnica (CIEB, 2018). De modo similar aos referenciais da SBC, o CIEB utiliza três eixos para organizar o conhecimento, embora levemente diferentes dos da SBC: Pensamento Computacional, Cultural Digital e Tecnologia Digital. Cada um dos eixos é subdividido em conceitos, para os quais são elencados habilidades. Para cada habilidade, são propostas práticas pedagógicas, avaliações e materiais de referência, além de relacionar cada habilidade com as habilidades e competências da BNCC. Neste sentido, embora o currículo do CIEB não apresente um conjunto de livros didáticos como o nosso, ele possui um nível de detalhamento maior do que os referenciais e diretrizes da SBC, permitindo a construção de implementações curriculares com certa facilidade. Nosso currículo, por outro lado, apresenta um itinerário claro, com aumento gradual de complexidade e encadeamento de conceitos e contextos que privilegiam a aprendizagem em espiral, significativa e contextualizada.

\footnotetext{
${ }^{18}$ https://teachcomputing.org/curriculum
} 


\section{Conclusões}

Este artigo descreveu o currículo Computação Fundamental, uma implementação detalhada de currículo de computação para o Ensino Fundamental II do Brasil. Este currículo é fundamentado na aprendizagem em espiral, na aprendizagem significativa, no construcionismo e na contextualização da aprendizagem de computação, além de se sustentar nos referenciais curriculares da CSTA. Os recursos didáticos associados foram compostos de modo a oferecer um guia para os professores com planejamentos associados e roteiros de aula, além de oferecer aos estudantes descrições importantes dos tópicos de computação e um conjunto de atividades práticas e reflexivas.

O currículo apresenta desafios de implementação: infraestrutura, capacitação e integração curricular. Em termos de infraestrutura, desenhamos o currículo para aquisição gradual de equipamentos e materiais. Os guias detalhados facilitam a adaptação dos professores, embora entendamos ser importante um processo de capacitação adequado. Para integração curricular, há várias opções de uso dos recursos didáticos associados, embora a existência de uma disciplina de computação com duas horas semanais facilite a integração.

A organização do currículo em espiral permite solidificar os conhecimentos adquiridos pelos estudantes. Utilizando conhecimentos prévios, procura-se alcançar níveis de aprendizagem mais significativos. Contextualizando o currículo em torno de temáticas de interesse dos estudantes, espera-se manter níveis de engajamento e motivação mais elevados. Construindo artefatos físicos e lógicos, os estudantes podem querer se apropriar dos conhecimentos, alcançando retenção mais profunda e interesse na temática. Integrando conceitos de computação com matemática, ciências e linguagem, permite-se que a computação atravesse o currículo escolar, levando a soluções mais interdisciplinares de projetos escolares.

Os principais desdobramentos deste currículo vão depender, em essência, de seu uso e estudo por professores e pesquisadores. Entendemos que o currículo Computação Fundamental tem potencial para ser testado, apropriado e modificado pela comunidade.

Para a comunidade de professores, são oferecidos instrumentos detalhados para a prática do ensino e aprendizagem de computação no Ensino Fundamental II. Para os professores de computação em formação, seja na Licenciatura em Computação, seja na formação em serviço de professores de outras áreas, a existência de guias detalhados como os existentes nos livros didáticos aqui apresentados permite uma ação mais sistemática nas atividades de prática e estágio. Embora os recursos tenham sido desenvolvidos para o Ensino Fundamental II, acreditamos que podem ser reusados em outros níveis educacionais, especialmente na educação profissional de nível médio, reduzindo a complexidade e a abstração das disciplinas técnicas comumente ancoradas em materiais didáticos desenvolvidos para a educação superior.

Para a comunidade de pesquisadores, é oferecida uma implementação detalhada de currículo sobre a qual é possível refletir, analisar, debater e reconstruir, levando a novas ideias e experiências curriculares na educação básica. Entendemos que este não é um currículo acabado, mas um dos primeiros passos na construção de currículos nacionais e regionais de computação na educação básica. Este currículo pode ser testado, confrontado, modificado, melhorado e até mesmo substituído. Mas terá cumprido seu papel se servir para debater esta construção curricular que se faz premente na comunidade acadêmica brasileira.

Em trabalhos futuros, pretendemos implementar o currículo em escolas do Brasil, espe- 
cialmente no Estado da Bahia, onde já encontramos espaço para projetos-piloto de integração curricular oficial. Nestes espaços, pretendemos avaliar o currículo desenvolvido e os recursos didáticos sob diferentes perspectivas, como a aquisição de habilidades de computação e de habilidades processuais chamadas de habilidades do Século XXI. Pretendemos também avaliar os livros didáticos desenvolvidos na perspectiva de sua adequação didática e através de rubricas específicas para avaliação de currículos, além de melhor relacionar o currículo desenvolvido com a BNCC.

\section{Artigo Premiado Estendido}

Esta publicação é uma versão estendida do $3^{\circ}$ melhor artigo do Workshop de Informática na Escola (WIE 2020), intitulado "Computação e o Mundo: Uma Proposta de Educação em Computação para o Nono Ano do Ensino Fundamental II”, DOI: 10.5753/cbie.wie.2020.21.

\section{Referências}

Araujo, L. G. J., Santana, B. L., \& Bittencourt, R. A. (2019a). Computação e Comunidade: Livro do Estudante. Feira de Santana: Edição do Autor. [GS Search]

Araujo, L. G. J., Santana, B. L., \& Bittencourt, R. A. (2019b). Computação e Comunidade: Livro do Professor. Feira de Santana: Edição do Autor. [GS Search]

Araujo, L. G. J., Santana, B. L., \& Bittencourt, R. A. (2019c). Computação e Comunidade: Uma Proposta de Educação em Computação para o Sétimo Ano do Ensino Fundamental II. In Anais do XXV Workshop de Informática na Escola (pp. 325-334). SBC. doi: 10.5753/cbie.wie.2019.325 [GS Search]

Araujo, L. G. J., Santana, B. L., \& Bittencourt, R. A. (2020a). Computação e o Mundo: Livro do Estudante. Feira de Santana: Edição do Autor. [GS Search]

Araujo, L. G. J., Santana, B. L., \& Bittencourt, R. A. (2020b). Computação e o Mundo: Livro do Professor. Feira de Santana: Edição do Autor. [GS Search]

Araujo, L. G. J., Santana, B. L., \& Bittencourt, R. A. (2020c). Computação e o Mundo: Uma Proposta de Educação em Computação para o Nono Ano do Ensino Fundamental II. In Anais do XXVI Workshop de Informática na Escola (pp. 21-30). SBC. doi: 10.5753/cbie.wie.2020.21 [GS Search]

Ausubel, D. P. (1960). The use of advance organizers in the learning and retention of meaningful verbal material. Journal of Educational Psychology, 51(5), 267. doi: 10.1037/h0046669 [GS Search]

Bargury, I. Z., Haberman, B., Cohen, A., Muller, O., Zohar, D., Levy, D., \& Hotoveli, R. (2012). Implementing a new Computer Science Curriculum for middle school in Israel. In 2012 Frontiers in Education Conference (p. 1-6). doi: 10.1109/FIE.2012.6462365 [GS Search]

Becker, B. A., \& Quille, K. (2020). Computer Science for Leaving Certificate (1st ed.). Dublin, Ireland: Golden Key. [GS Search]

Bell, T. (2013). Computer Science Field Guide. New Zealand: University of Canterbury. Retrieved from https://csfieldguide.org.nz/en/

Bell, T., Andreae, P., \& Lambert, L. (2010). Computer Science in New Zealand high schools. In Proceedings of the Twelfth Australasian Conference on Computing Education - Volume 103 (pp. 15-22). [GS Search]

Bordini, A., Avila, C. M. O., Weisshahn, Y., da Cunha, M. M., da Costa Cavalheiro, S. A., Foss, L., ... Reiser, R. H. S. (2016). Computaçao na educaçao básica no brasil: O estado da arte. Revista de Informática Teórica e Aplicada, 23(2), 210-238. doi: 10.22456/2175-2745.64431 [GS Search]

Boyd, D., \& Marwick, A. E. (2011). Social Privacy in Networked Publics: Teens' Attitudes, Practices, and 
Strategies. In A decade in Internet Time: Symposium on the Dynamics of the Internet and Society. [GS Search]

Brasil/MEC (2018). Base Nacional Comum Curricular. Retrieved from http://basenacionalcomum.mec .gov.br/images/BNCC_EI_EF_110518_versaofinal_site.pdf

Bruner, J. (1966). Uma Nova Teoria de Aprendizagem. Rio de Janeiro: Bloch. [GS Search]

Castells, M. (1996). The information age (Vol. 98). Oxford Blackwell Publishers. [GS Search]

Choi, J., An, S., \& Lee, Y. (2015). Computing education in Korea-current issues and endeavors. ACM Transactions on Computing Education (TOCE), 15(2), 1-22. [GS Search]

CIEB (2018). Currículo de Tecnologia e Computação da Educação Infantil ao Ensino Fundamental. http://curriculo.cieb.net.br/.

Computer Science Teachers Association (2017). CSTA K-12 Computer Science Standards, Revised 2017. http://www.csteachers.org/standards. [GS Search]

Computing at School (2021). Computing at School. https://www.computingatschool.org.uk/.

CSforAll (2021). Computer Science for All. https://www.csforall.org/.

diSessa, A. A. (2018). Computational Literacy and"The Big Picture"Concerning Computers in Mathematics Education. Mathematical Thinking and Learning: An International Journal, 20(1), 3-31. doi: 10.1080/10986065.2018.1403544 [GS Search]

Fowler, B., \& Vegas, E. (2021). How England implemented its computer science education program. Retrieved from http://files.eric.ed.gov/fulltext/ED610629.pdf

Guzdial, M. (2019). Computing for Other Disciplines. In S. A. Fincher \& A. V. Robins (Eds.), The Cambridge Handbook of Computing Education Research (p. 584-605). Cambridge University Press. doi: 10.1017/9781108654555.020 [GS Search]

Guzdial, M., \& Forte, A. (2005). Design process for a non-majors computing course. ACM SIGCSE Bulletin, 37(1), 361-365. doi: 10.1145/1047124.1047468 [GS Search]

Guzdial, M. J., \& Ericson, B. (2015). Introduction to Computing and Programming in Python: A Multimedia Approach. Pearson. [GS Search]

Hazzan, O., Gal-Ezer, J., \& Blum, L. (2008). A Model for High School Computer Science Education: The Four Key Elements That Make It! In Proceedings of the 39th Technical Symposium on Computer Science Education (pp. 281-285). ACM. doi: 10.1145/1352135.1352233 [GS Search]

Herr, N. (2008). The sourcebook for teaching science, grades 6-12: Strategies, activities, and instructional resources. John Wiley \& Sons. [GS Search]

Hubwieser, P., Giannakos, M. N., Berges, M., Brinda, T., Diethelm, I., Magenheim, J., ... Jasute, E. (2015). A global snapshot of computer science education in K-12 schools. In Proceedings of the 2015 ITiCSE on working group reports (pp. 65-83). doi: 10.1145/2858796.2858799 [GS Search]

López, P. E. F. M., Aloi, F., Ciolek, D. A., Martínez, F., Pari, D., \& Tobia, P. (2019). Manual: Ciencias de la Computación para el aula: 1er. ciclo de secundaria. https://campuseducativo.santafe.edu.ar/ manual-ciencias-de-la-computacion-para-el-aula-1-ciclo-de-secundaria/.

Mioto, F., Petri, G., von Wangenheim, C. G., Borgatto, A. F., \& Pacheco, L. H. M. (2019). bASES21-Um Modelo para a Autoavaliação de Habilidades do Século XXI no Contexto do Ensino de Computação na Educação Básica. Revista Brasileira de Informática na Educação, 27(01), 26. doi: 10.5753/rbie.2019.27.01.26 [GS Search]

Observatório Softex (2012). Software e serviços de TI: a indústria brasileira em perspectiva (Vol. 2). Retrieved from https://softex.br/download/cadernos-tematicos-2012-observatorio-softex -industria-brasileira-software-servicos-ti-em-perspectiva-versao-completa-portugues/ [GS Search]

OCS at CPS (2021). Office of Computer Science at Chicago Public Schools. https://sites.google.com/ cps.edu/cs4all/.

Papert, S. (1986). Constructionism: A New Opportunity for Elementary Science Education. MIT Media Lab. [GS Search] 
Papert, S., \& Solomon, C. (1971). Twenty things to do with a computer. Educational Technology Magazine. [GS Search]

Pressman, R. S. (2011). Engenharia de software - uma abordagem profissional (7th ed.). AMGH Editora Ltda. [GS Search]

Resnick, M. (2012). Point of view: Reviving Papert's dream. Educational Technology, 52(4), 42. Retrieved from https://www.jstor.org/stable/44430058 [GS Search]

Royal Society (2012). Shut down or restart? The way forward for computing in UK schools. The Royal Society, London. [GS Search]

Santana, B. L., Araujo, L. G. J., \& Bittencourt, R. A. (2019a). Computação e Eu: Livro do Estudante. Feira de Santana: Edição do Autor. [GS Search]

Santana, B. L., Araujo, L. G. J., \& Bittencourt, R. A. (2019b). Computação e Eu: Livro do Professor. Feira de Santana: Edição do Autor. [GS Search]

Santana, B. L., Araujo, L. G. J., \& Bittencourt, R. A. (2019c). Computação e Eu: Uma Proposta de Educação em Computação para o Sexto Ano do Ensino Fundamental II. In Anais do XXVII Workshop sobre Educação em Computação (pp. 21-30). SBC. doi: 10.5753/wei.2019.6613 [GS Search]

Santana, B. L., Araujo, L. G. J., \& Bittencourt, R. A. (2020a). Computação e Sociedade: Livro do Estudante. Feira de Santana: Edição do Autor. [GS Search]

Santana, B. L., Araujo, L. G. J., \& Bittencourt, R. A. (2020b). Computação e Sociedade: Livro do Professor. Feira de Santana: Edição do Autor. [GS Search]

Santana, B. L., Araujo, L. G. J., \& Bittencourt, R. A. (2020c). Computação e Sociedade: Uma Proposta de Educação em Computação para o Oitavo Ano do Ensino Fundamental II. In Anais do XXVI Workshop de Informática na Escola (pp. 81-90). SBC. doi: 10.5753/cbie.wie.2020.81 [GS Search]

Santos, P. S., Araujo, L. G. J., \& Bittencourt, R. A. (2018). A Mapping Study of Computational Thinking and Programming in Brazilian K-12 Education. In 2018 IEEE Frontiers in Education Conference (FIE) (pp. 1-8). IEEE. doi: 10.1109/FIE.2018.8658828 [GS Search]

SBC (2017). Referenciais de Formação em Computação: Educação Básica. Retrieved from http://www .sbc.org.br/files/ComputacaoEducacaoBasica-versaofinal-julho2017.pdf

SBC (2018). Diretrizes para Ensino de Computação na Educação Básica. Retrieved from https://www.sbc.org.br/documentos-da-sbc/send/203-educacao-basica/1220-bncc-em-itinerario -informativo-computacao-2

Seehorn, D., Carey, S., Fuschetto, B., Lee, I., Moix, D., O’Grady-Cunniff, D., ... Verno, A. (2011). CSTA K-12 Computer Science Standards: Revised 2011 (Tech. Rep.). New York, NY, USA: CSTA/ACM. Retrieved from http://files.eric.ed.gov/fulltext/ED610629.pdf

Solomon, C., Harvey, B., Kahn, K., Lieberman, H., Miller, M. L., Minsky, M., ... Silverman, B. (2020). History of Logo. Proc. ACM Program. Lang., 4(HOPL), 1-66.

Szabo, C., Sheard, J., Luxton-Reilly, A., Becker, B. A., \& Ott, L. (2019). Fifteen years of introductory programming in schools: a global overview of K-12 initiatives. In Proc. of the 19th Koli Calling Int. Conf. on Computing Education Research (pp. 1-9). [GS Search]

Wing, J. M. (2006). Computational thinking. Communications of the ACM, 49(3), 33-35. doi: 10.1145/1118178.1118215 [GS Search] 